\title{
Comparative genomic analysis of nine Sphingobium strains: insights into their evolution and hexachlorocyclohexane $(\mathrm{HCH})$ degradation pathways
}

Helianthous Verma ${ }^{1 \dagger}$, Roshan Kumar ${ }^{1 \dagger}$, Phoebe Oldach ${ }^{1}$, Naseer Sangwan ${ }^{1}$, Jitendra P Khurana ${ }^{2}$, Jack A Gilbert ${ }^{3,4}$ and Rup Lal ${ }^{1 *}$

\begin{abstract}
Background: Sphingobium spp. are efficient degraders of a wide range of chlorinated and aromatic hydrocarbons. In particular, strains which harbour the lin pathway genes mediating the degradation of hexachlorocyclohexane $(\mathrm{HCH})$ isomers are of interest due to the widespread persistence of this contaminant. Here, we examined the evolution and diversification of the lin pathway under the selective pressure of $\mathrm{HCH}$, by comparing the draft genomes of six newly-sequenced Sphingobium spp. (strains LL03, DS20, IP26, HDIPO4, P25 and RL3) isolated from HCH dumpsites, with three existing genomes (S. indicum B90A, S. japonicum UT26S and Sphingobium sp. SYK6).

Results: Efficient HCH degraders phylogenetically clustered in a closely related group comprising of UT26S, B90A, HDIPO4 and IP26, where HDIPO4 and IP26 were classified as subspecies with ANI value $>98 \%$. Less than $10 \%$ of the total gene content was shared among all nine strains, but among the eight $\mathrm{HCH}$-associated strains, that is all except SYK6, the shared gene content jumped to nearly $25 \%$. Genes associated with nitrogen stress response and two-component systems were found to be enriched. The strains also housed many xenobiotic degradation pathways other than $\mathrm{HCH}$, despite the absence of these xenobiotics from isolation sources. Additionally, these strains, although non-motile, but posses flagellar assembly genes. While strains HDIPO4 and IP26 contained the complete set of lin genes, DS20 was entirely devoid of lin genes (except linKLMN) whereas, LL03, P25 and RL3 were identified as lin deficient strains, as they housed incomplete lin pathways. Further, in HDIPO4, linA was found as a hybrid of two natural variants i.e., linA1 and linA2 known for their different enantioselectivity.

Conclusion: The bacteria isolated from $\mathrm{HCH}$ dumpsites provide a natural testing ground to study variations in the lin system and their effects on degradation efficacy. Further, the diversity in the lin gene sequences and copy number, their arrangement with respect to IS6100 and evidence for potential plasmid content elucidate possible evolutionary acquisition mechanisms for this pathway. This study further opens the horizon for selection of bacterial strains for inclusion in an $\mathrm{HCH}$ bioremediation consortium and suggests that HDIPO4, IP26 and B90A would be appropriate candidates for inclusion.
\end{abstract}

Keywords: Hexachlorocyclohexane (HCH), Sphingobium, lin genes, Xenobiotic compounds

\footnotetext{
*Correspondence: rupla|@gmail.com

'Equal contributors

'Room No. 115, Molecular Biology Laboratory, Department of Zoology,

University of Delhi, Delhi 110007, India

Full list of author information is available at the end of the article
} 


\section{Background}

The family Sphingomonadaceae has been subdivided into five genera: Sphingomonas, Sphingobium, Novosphingobium, Sphingopyxis and Sphingosinicella [1,2]. To date, the genomes of nearly 40 sphingomonads have been sequenced, which has revealed the genetic basis for the degradation of a broad range of polycyclic aromatic hydrocarbons (PAH) and polysaccharides [3]. However, Sphingobium spp. are of particular interest due to their ability to degrade hexachlorocylcohexane $(\mathrm{HCH})$. The majority of $\mathrm{HCH}$ isomers (i.e. $\alpha, \beta, \delta, \varepsilon$ ) are formed during the production of the insecticide lindane $(\gamma-\mathrm{HCH})$, and have been active pollutants since the 1950s [4]. Among all these isomers, only $\gamma-\mathrm{HCH}$ has insecticidal properties. Purification of $\gamma-\mathrm{HCH}(10-12 \%)$ from the mixture leads to the formation of $\mathrm{HCH}$ muck (88-90\% of the total $\mathrm{HCH}$ mixture) having mainly $\alpha(60-70 \%), \beta(5-12 \%), \delta(6-10 \%)$, and $\varepsilon$ (3-4\%) isomers [5]. This has been generally discarded in the open by the side of industrial units creating a large number of $\mathrm{HCH}$ dumpsites between the 1960s to the 1980s around the world [6]. Sphingobium spp. are often enriched in $\mathrm{HCH}$ dumpsites and have been shown to acquire and maintain genes associated with $\mathrm{HCH}$ degradation [7-10].

The degradation potential for $\mathrm{HCH}$ isomers has been attributed to the lin pathway (Figure 1), which has been studied in detail in both Sphingobium japonicum UT26S $[11,12]$ and Sphingobium indicum B90A [6]. The lin pathway is subdivided into an upper degradation pathway consisting of $\mathrm{HCH}$ dehydrochlorinase (LinA), haloalkane dehalogenase (LinB) and dehydrogenase ( $\operatorname{LinC} / \operatorname{LinX})$, and a lower degradation pathway consisting of reductive dechlorinase (LinD), ring cleavage oxygenase (LinE), maleylacetate reductase (LinF), an acyl-CoA transferase (LinG, H), a thiolase (LinJ) and transcription factors (LinI and LinR). The LinK, LinL, LinM and LinN i.e., a permease,

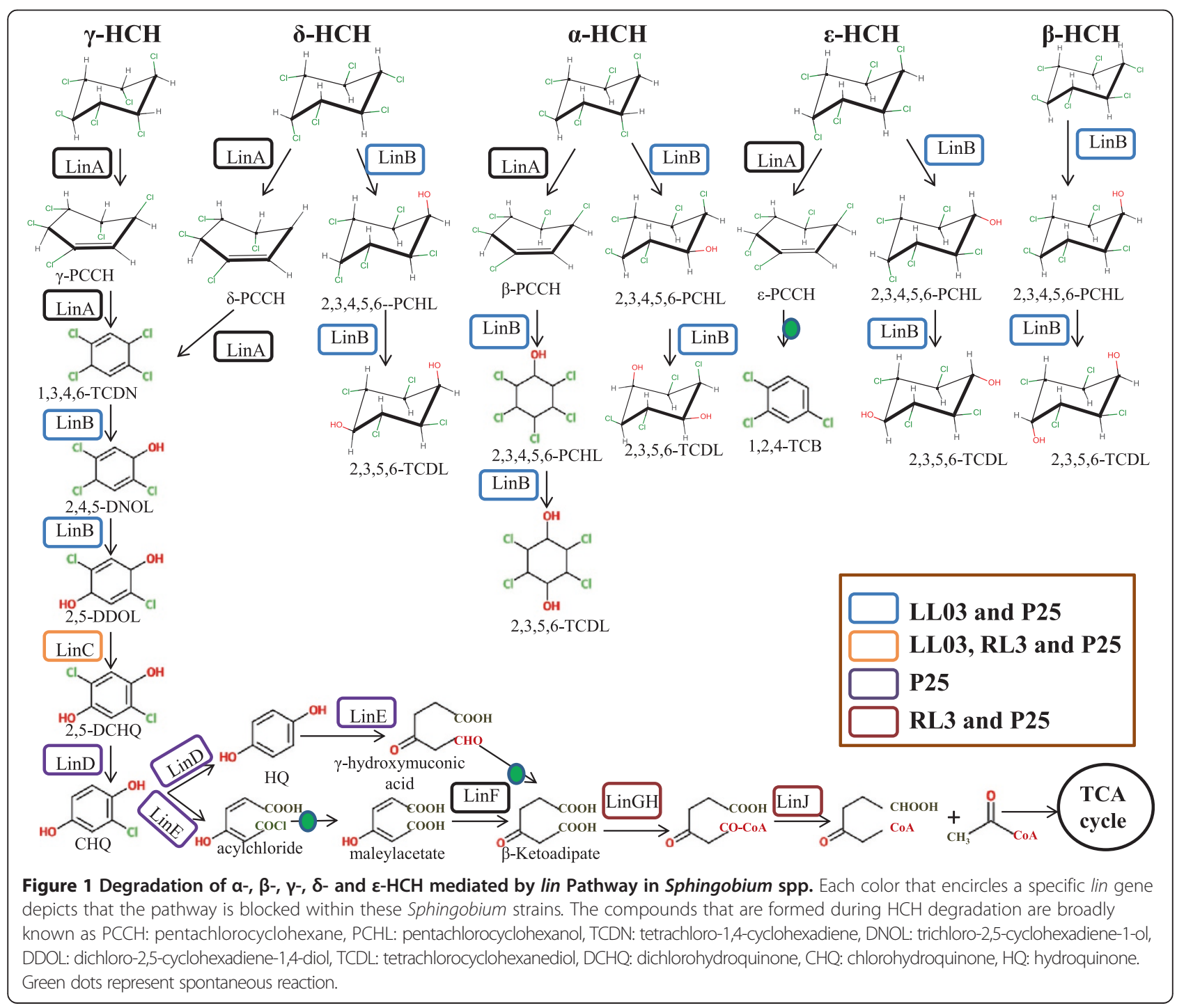


ATPase, periplasmic protein and a lipoprotein respectively, together constitute a putative ABC-type transporter [6].

There is evidence that indicates high levels of polymorphisms in the amino acid sequences of the $\operatorname{lin} A$ and $\operatorname{lin} B$ genes. Further studies have revealed that these differences contribute to the efficacy of $\mathrm{HCH}$ degradation and substrate specificity [13]. While there are several strains of sphingomonads isolated from $\mathrm{HCH}$ dumpsites with demonstrated differences in $\mathrm{HCH}$ degradation ability $[8,14]$, genome-wide comparative analyses to better understand the lin pathway, localization of lin genes in the genome and methods of recruitment have not yet been undertaken.

In order to understand the evolution of the $\mathrm{HCH}$ degradation pathway, the draft genomes of six Sphingobium spp. isolated from $\mathrm{HCH}$ dumpsites and the complete genomes of three previously-sequenced, well-studied strains were analysed. Here, we characterize the genetic divergence between these strains in reference to the lin catabolic system and auxiliary characteristics associated with bioremediation potential. We also present evidence for possible plasmid and IS6100 based horizontal gene transfer (HGT) as the method for spread of the lin system genes among sphingomonads. Additionally, variation in the lin gene sequences is a matter of further investigation for improved degradation ability of these strains.

\section{Results and discussion}

\section{Genomic features of Sphingobium strains}

The genome sizes for the six newly sequenced Sphingobium spp. averaged 4.83 Mbp and ranged from 4.08 to $5.89 \mathrm{Mbp}$, with $S$. chinhatense IP26 maintaining the largest genome (Table 1). These sizes are consistent with existing Sphingobium spp. [15]. The variation in genome size can be partially correlated to the presence of genomic islands; IP26 maintained the largest genome and the highest genomic island content, while LL03 had the least (Table 1). This potentially reflects differential degrees of HGT and mobile genetic element acquisition among these strains. UT26S, B90A, IP26 and HDIPO4 all shared high sequence identity (>97\%), whereas LL03, P25, RL3 and DS20 have accumulated more sequence variation despite being under similar selection pressures (90-70\%) (Figure 2).

CRISPR elements were only found associated with S. baderi LL03 (22 spacers) and S. lactosutens DS20 (5 spacers). These spacer sequences are known bacterial defense mechanisms against viral and plasmid challenges acquired from foreign invading DNA, with the number of new phage-derived spacers being correlated with phage resistance [16]. However, their spacer sequences had no similarity to known viral phage sequences. Furthermore, LL03 maintained a type II CRISPR element with the cas9 gene involved in target interference, whereas DS20 had type I CRISPR elements with the cas3 gene [17]. Strains LLO3 and DS20 were isolated from $\mathrm{HCH}$ dumpsites in the Czech Republic and India, respectively, and these strains had two different CRISPR/CAS systems, that may correspond to their different geographical locations. These data also reflected that LL03 should have the greatest phage resistance.

\section{Comparative phylogenetic analysis}

Four different phylogenetic methods (16S rRNA gene sequence, single copy gene sequences, tetranucleotide frequency based correlation, and average nucleotide identity (ANI)) were used to analyze the relationships of the nine strains under study (Figure 3). The consensus tree topology obtained by these methods clustered $S$. indicum B90A, S. japonicum UT26S, S. chinhatense IP26, and Sphingobium sp. HDIPO4, with the exception of the single copy gene approach. Notably, these four strains were the only ones with an entirely complete lin pathway, thus suggesting convergent evolution through $\mathrm{HCH}$ selection pressure. Furthermore, ANI topology supported the grouping of Sphingobium sp. HDIPO4 and S. chinhatense IP26 as subspecies $(\geq 99.34 \%)$ (ANI values within the subspecies >98\%) [18]. The other five strains i.e., LL03, DS20, RL3, P25 and SYK6 did not produce a consensus phylogeny, with relationships differing between these approaches; in short, strains with the complete lin pathway formed a closed group whereas, the others have diverged. In addition, 16S rRNA and single copy gene approaches may be problematic for differentiation among highly related strains (as these methodologies do not consider the influence of HGT). However, ANI based pairwise comparison has clustered LL03 and RL3 (partial lin gene deficient but $\mathrm{HCH}$ degraders) in a monophyletic clade with P25 (partial lin gene deficient and slow $\mathrm{HCH}$ degrader) forming a close relationship. Moreover, DS20 and SYK6 (non-HCH degraders) were clustered together. This suggests that ANI based phylogeny is more appropriate and mirrors their relationship with respect to $\mathrm{HCH}$ degradation.

\section{Common gene content and functional profiling of Sphingobium spp.}

Core genome analysis identified 322 orthologs conserved between the nine genomes. The majority of these genes were involved in housekeeping functions such as the synthesis of ribosomal proteins, DNA replication, transcription \& translation machinery, amino acid metabolism and membrane transporters. Core genome analysis for the eight strains that were either isolated from an $\mathrm{HCH}$ dumpsite or showed $\mathrm{HCH}$ degradation potential (i.e. all except SYK6) predicted 880 orthologs (Figure 2), which suggests a significant increase in genomic conservation ( 2.7 times) resulting from the selective pressure of $\mathrm{HCH}$ exposure. This conservation is also seen in the degradation potential for other aromatic compounds such as 
Table 1 General characteristic features of the Sphingobium genomes

\begin{tabular}{|c|c|c|c|c|c|c|c|c|c|}
\hline Strains & IP26 & HDIPO4 & RL3 & P25 & DS20* & LLO3* & B90A & UT26S & SYK6 \\
\hline Project ID & PRJNA208542 & PRJNA201012 & PRJNA208544 & PRJNA201016 & PRJNA201649 & PRJNA202090 & PRJNA50313 & PRJDA19949 & PRJNA73353 \\
\hline NCBI Accession No. & AUDA00000000 & ATDO00000000 & AUWY00000000 & ATHO00000000 & ATDP00000000 & ATIB00000000 & AJXQ00000000 & $\begin{array}{l}\text { AP010803 to } \\
\text { AP010806 }\end{array}$ & $\begin{array}{l}\text { AP012222, } \\
\text { AP012223 }\end{array}$ \\
\hline Source of isolation & $\begin{array}{l}\text { HCH Dumpsite, } \\
\text { India }\end{array}$ & $\begin{array}{l}\text { HCH Dumpsite, } \\
\text { India }\end{array}$ & $\begin{array}{l}\text { HCH Dumpsite, } \\
\text { India }\end{array}$ & $\begin{array}{l}\text { HCH Dumpsite, } \\
\text { India }\end{array}$ & $\begin{array}{l}\text { HCH Dumpsite, } \\
\text { India }\end{array}$ & $\begin{array}{l}\text { HCH Dumpsite, } \\
\text { Czech Republic }\end{array}$ & $\begin{array}{l}\text { Rhizosphere } \\
\text { Soil, India }\end{array}$ & $\begin{array}{l}\text { Soil Contaminated } \\
\text { with } \gamma-\mathrm{HCH} \text {, Japan }\end{array}$ & $\begin{array}{l}\text { Waste water of } \\
\text { kraft mill pulp, } \\
\text { Japan }\end{array}$ \\
\hline HCH Degarder & Yes & Yes & Yes & No & No & No & Yes & Yes & No \\
\hline Genome Size (bp) & $5,894,129$ & $4,741,576$ & $4,754,053$ & $4,170,546$ & $5,360,246$ & $4,848,216$ & $4,082,196$ & $4,424,878$ & $4,348,133$ \\
\hline $\mathrm{G}+\mathrm{C}$ content $(\%)$ & 64.5 & 65.5 & 65 & 64.7 & 63.6 & 64 & 65.8 & 65.6 & 66 \\
\hline Predicted CDS & 4646 (5161068 bp) & 4646 (4105641 bp) & 4636 (4152861 bp) & 4033 (3644184 bp) & 5288 (4682346 bp) & 4914 (4312911 bp) & 3976 (3570642 bp) & 4414 (3929727 bp) & 4097 (3825558 bp) \\
\hline Pseudogenes & 10 & 46 & 2 & 70 & 45 & 39 & - & - & - \\
\hline $\begin{array}{l}\text { Average Gene } \\
\text { Size (bp) }\end{array}$ & 903 & 889 & 896 & 903 & 890 & 852 & 886 & 890 & 933 \\
\hline$\%$ of CDS & $87.56 \%$ & $86.58 \%$ & $87.35 \%$ & $87.38 \%$ & $88.31 \%$ & $88.96 \%$ & $87.46 \%$ & $88.80 \%$ & $87.98 \%$ \\
\hline IS6100 & 21 & 18 & 19 & 24 & 15 & 22 & 11 & 5 & 0 \\
\hline tRNA & 66 & 54 & 56 & 49 & 59 & 56 & 54 & 55 & 50 \\
\hline rRNA & 11 & 13 & 12 & 9 & 15 & 12 & 3 & 9 & 6 \\
\hline Genomic islands (bp) & 1104688 & 705420 & 180116 & 201158 & 179141 & 48062 & 427792 & 395714 & 244403 \\
\hline
\end{tabular}






benzoate, 1,4-dichlorobenzene, 1,2-methylnapthalene, caprolactam, toluene and xylene, trinitrotoluene, biphenyl and styrene degradation (Figure 4). Genes involved in the degradation of p-hydroxybenzoate, benzoate, quinate, gentisare, and catechol were also identified in the nine Sphingobium genomes (Additional file 1: Table S1). The presence of degradation pathways for phenol/toluene, chlorophenol, anthranilate, and homogentisate are identified in UT26S [19]. These pathways were observed in at least two of the newly sequenced strains (Additional file 1: Table S1). This suggests that these Sphingobium spp. possess broad aromatic compound degradation potential, although we did not observe the presence of these compounds at the $\mathrm{HCH}$ dumpsite [20]. The link between these aromatic degradation pathways and the $\mathrm{HCH}$ degradation pathway requires further investigation.
Functional profiling was used to analyze pathways that were differentially enriched in these strains. For this, a dendogram was constructed based upon the top 50 subsystems at $0.8 \%$ minimum abundance using pearson correlation distance. The analysis revealed that the two-component system for gene expression was highly abundant in all of the Sphingobium genomes (Figure 4). This system is known to facilitate adaptation to extreme environmental conditions and likely contributes to the ability to survive in conditions of high $\mathrm{HCH}$ pressure, salinity, and acidity that exist at the $\mathrm{HCH}$ dumpsite [9]. Additionally, the nine strains collectively showed an abundance of ABC transporters within their genomes. The abundance of these transporters implies that these strains are highly engaged in transport of a wide variety of substrates across extraand intracellular membranes [21], which is consistent with 


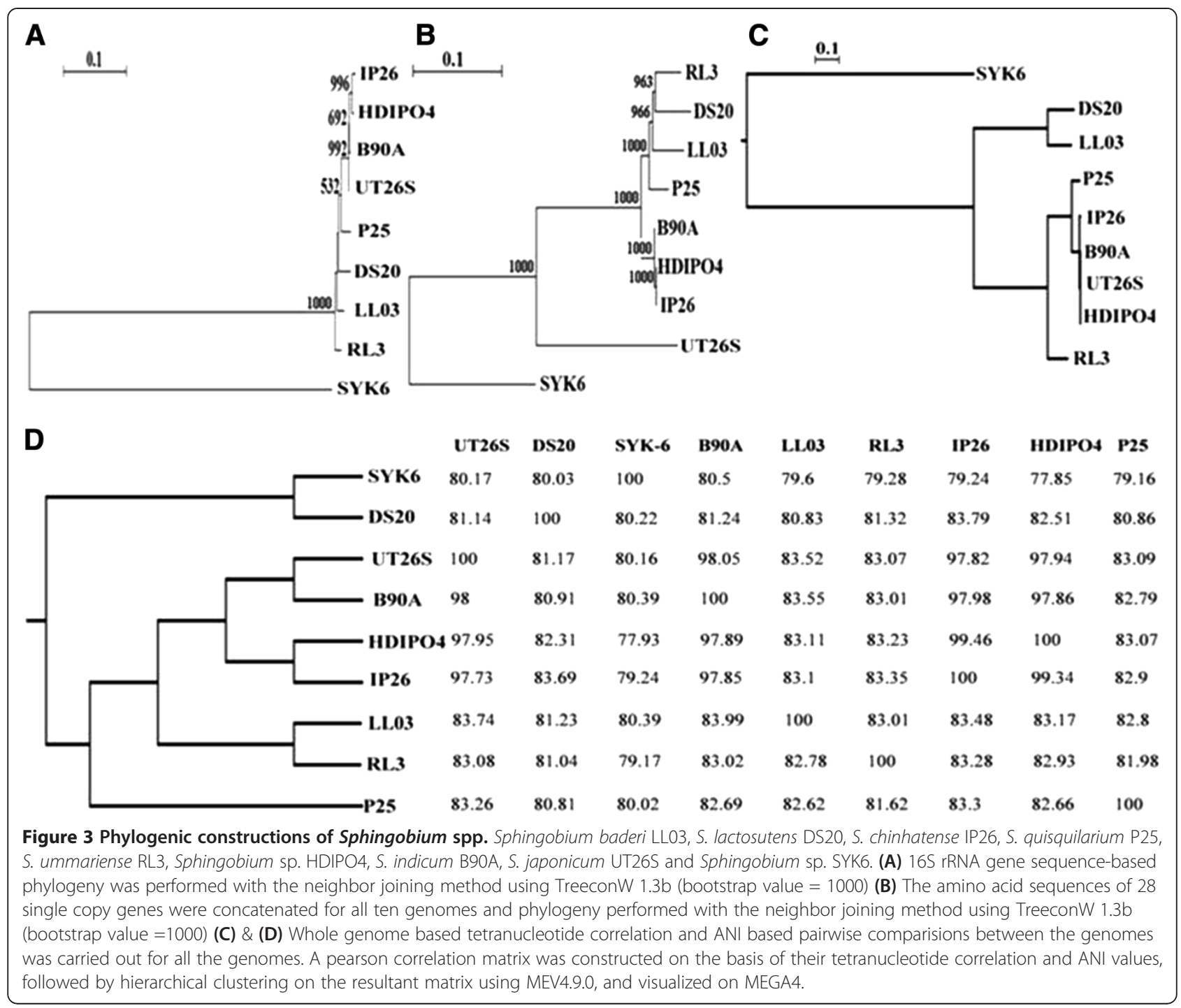

the Sphingobium proficiency for degradation of a wide range of xenobiotics (mentioned above; Figure 4).

Interestingly, HDIPO4 and IP26, which had a close phylogenetic relationship, demonstrated differences in their functional repertoire, based on the top 50 subsystems. This is primarily driven by an increased abundance of 1,4-dichlorobenzene degradation, toluene and xylene degradation, caprolactam degradation, PPAR signaling and atrazine degradation pathways in HDIPO4, which was clustered with functional profiling of P25 and UT26S as they shared these enrichments. Furthermore, lipopolysaccharide biosynthesis, tyrosine metabolism, glycan and glycosaminoglycan degradation pathways were found enriched in IP26 as compared to HDIPO4. This variation suggests that while these strains exhibit similar genomic content, they exhibit differential dominance in their metabolic preferences.
Nitrogen assimilation and the presence of flagellar genes in non-motile Sphingobium

The genomes of all the nine strains were found to contain an enrichment of the two component signal transduction system for nitrogen stress response (NtrC pathway) . Additionally, the large subunit of assimilatory nitrate reductase, a key regulator that potentially enables the utilization of nitrate as a nitrogen source, was found to be under diversifying natural selection $(\mathrm{dN} / \mathrm{dS}=1.09)$, which suggests that these strains can tolerate low inorganic nitrogen concentrations and are evolving in response to this inorganic nitrogen stress. At high nitrogen concentration, the transmembrane protein $\ln C$ (ntrB/ Histidine kinase) responds to nitrogen availability and phosphorylates $\operatorname{gln} G(n \operatorname{tr} C)$, which in turn leads to the activation of $g \ln A$ (glutamine synthetase) [22]. Another key regulator of the pathway is $g \ln B$, which interacts 




Figure 4 Functional profiling of the Sphingobium genomes. Heat map showing the normalized relative abundance of the top 50 subsystems enriched in the nine Sphingobium genomes. The strains and enriched pathways were clustered using Pearson correlation with a $0.8 \%$ minimum abundance. The color scale represents the relative abundance of gene content for each pathway, normalized by sample mean.

and regulates the activity of $g \ln C$. When the nitrogen availability is low, $g \ln B$ is subjected to post transcriptional modification by uridylation (mediated by $g \ln D$ ). This modification is reversed in $\mathrm{N}$-sufficient conditions [22]. Thus, the presence of $\mathrm{NtrC}$ pathway and nitrate reductase genes explains the ongoing phenomena of nitrogen assimilation by these strains at $\mathrm{HCH}$ dumpsites to acclimatize themselves in such nitrate concentrations. Increasing exposure to elevated hydrocarbon concentrations was found to be positively correlated with the relative abundance of genes associated with nitrogen metabolism [23].

The $N \operatorname{trC}$ pathway is also associated with genes regulating chemotactic response, such as $\operatorname{che} Y$, motA, motB, and flagellar biosynthesis proteins, such as $f l h A, f l i O, f l i P, f l i R$ etc. All these genes were also found in the core-genome. che $Y$ modulates the cell's ability to interact with the flagellum and controls swimming behavior [24]. Interestingly, while these Sphingobium strains are considered non-motile [25-30], each genome housed more than half of the genes needed for flagellar assembly and functioning. This raises the possibility that they are either in a process of acquiring or losing motility. The abundance of chemotaxis and motility genes has already been demonstrated in the metagenome of the $\mathrm{HCH}$ dumpsite [9] from where HDIPO4, IP26, P25, DS20, and RL3 were isolated. However, further analysis is needed to probe the reason for retention or loss of flagellar genes in the Sphingobium strains, and to investigate whether Sphingobium have the potential to gain motility through acquisition of the remaining genes under the high selective pressure of $\mathrm{HCH}$ in the stressed environments.

\section{Recruitment of lin pathway through different routes}

The genome analysis revealed a mosaic distribution of lin genes and IS6100 elements in HCH-degrading Sphingobium spp. coupled with high polymorphism levels in the lin genes. This indicates the recruitment of $\operatorname{lin}$ genes through 
different routes in Sphingobium spp. under $\mathrm{HCH}$ stress, and further that the pathway has not yet stabilized in these strains but is instead subjected to further rearrangements and polymorphisms.

\section{IS6100-mediated recruitment based on mosaic distribution pattern of lin genes}

The IS6100 elements, known for disseminating lin genes through HGT among sphingomonads [7,31-33], were found to be present in all of the newly sequenced strains associated with $\mathrm{HCH}$ degradation, including strain DS20 which did not degrade $\mathrm{HCH}$. The number, as determined from the genome sequence, varied from 5 copies in UT26S to 24 copies in P25 (Table 1). The presence of a large number of IS6100 elements reflects a high degree of genomic rearrangement, as the IS6100 elements have already been demonstrated to play an important role in the spread and reorganization of the lin pathway in sphingomonads [7,10,31-33].

To further explore the mechanism of HGT in the spread and diversification of the lin system, we examined the colocalization of lin genes with mobile elements such as the insertion sequence IS6100 and transposons, and their presence on plasmids. In all of strains where $\operatorname{lin} A$ gene was present in, it was found in nearly identical association with IS elements as in UT26S i.e. IS6100 was found within proximity of $<5 \mathrm{Kbp}$. However, in RL3, two IS6100 copies lies in the same orientation within the above mentioned range. Hence, this suggests that among these strains the association of $\operatorname{lin} A$ with IS6100 is consistent, but the reason and possible involvement of IS6100 in the mechanism of duplication of the $\operatorname{lin} A$ gene in RL3 needs to be identified.

In IP26, $\operatorname{lin} B$ was found to be flanked on both sides by IS6100 (Figure 5A). Additionally, resolvase genes were found at the flanking ends of both of these transposons. Strains LL03 and P25 did not contain the $\operatorname{linB}$ gene, as confirmed by PCR amplication. Thus, either these strains have yet to acquire the $\operatorname{lin} B$ gene, or, given the flanking IS6100 elements, it is suggested that the loss of $\operatorname{lin} B$ could have occurred via an intra-chromosomal single homologous recombination between two copies of IS6100 $[19,10]$.

In HDIPO4, a truncated copy of linF along with complete set of $\operatorname{lin} C$ and $\operatorname{lin} B$ was found with an IS6100 element (length of the segment $=15 \mathrm{Kbp}$ ) (Figure $5 \mathrm{~B}$ ). In contrast, in the case of the reference UT26S, these elements were dispersed, with $\operatorname{lin} F$ present on chromosome 2 and $\operatorname{lin} B$ and $\operatorname{lin} C$ on chromosome 1 . The association of these three elements suggests that they may have been brought together by IS6100-mediated transposition, a hypothesis supported by the fact that HDIPO4 contains a high number of IS6100 comparable to UT26S (Table 1), and that they may be in the process of forming an operon.

Of the three copies of linDER present in RL3, one was closely associated with the $h m g B$ and $h m g A$ genes of the homogentisate degradation pathway, separated by a copy of IS6100 (Figure 5B). In contrast, in UT26S, linDER was housed on a plasmid (pCHQ1), while $h m g B$ and $h m g A$ were found on chromosome 2 [19]. Therefore, in RL3, it is possible that these two different aromatic compound degradation pathways were brought into close proximity by IS6100 mediated transposition. Thus, IS6100, apart from the spread of lin gene system, might be effective in the spread of homogentisate pathways despite the absence of homogentisate selective pressure at the $\mathrm{HCH}$ dumpsite, consistent with the fact that already sphingomonads that degrade aromatic hydrocarbons were found to contain catabolic genes associated with IS6100 [34].

In strain LL03, isolated from the Czech Republic, linGHIJ genes were associated with IS6100, whereas in the UT26S genome, isolated from Japan, IS6100 was absent from the region proximal to these lower pathway genes. As IS6100 is reported to be a key driver in the recruitement of the lin system [6], differential organization of the IS6100 element with respect to lin genes for strains from geographically-disparate locations reflects an ongoing IS6100-driven evolution of the lin system, including the lower degradation pathway components such as linGHIJ.

IS6100 elements have also been found in the genome of DS20, which did not degrade $\mathrm{HCH}$ isomers (due to the lack of lin genes except linKLMN). However, in DS20, the regions flanking the IS6100 elements comprised a variety of xenobiotic tolerance and degradation genes (i.e., benzene 1,2-dioxygenase, CopA family copper resistance protein, maleylacetatereductase, a putative efflux protein, chlorocatechol 1,2-dioxygenase), which further supports the role of IS6100 in distributing genes for a broad-range of such functions in Sphingobium spp. The fact that DS20, a non- $\mathrm{HCH}$ degrader, maintained 15 copies of IS6100 elements clearly suggests the potential of this strain to acquire lin genes through IS6100 mechanisms in the future.

\section{Plasmid mediated recruitment}

In investigating the presence and spread of the lin genes, the recently sequenced genome of an $\mathrm{HCH}$-degrader Sphingomonas sp. MM-1 is of interest as it was found to have five plasmids housing the genes of the lin pathway [35]. In the MM-1 genome, the $\operatorname{lin} F$ was found on PISP0; $\operatorname{lin} A, \operatorname{lin} C$, and a truncated $\operatorname{lin} F$ on pISP1, linDER on pISP3, and $\operatorname{lin} B$, $\operatorname{lin} C$, and another truncated $\operatorname{lin} F$ on pISP4 [35] and linGHIJ was found on pISP0. Genes for an ABC transporter were found on the chromosome, but these did not share at least $80 \%$ identity to the $\operatorname{lin} K L M N$ genes of UT26S. In addition to this, in strain UT26S, HCH-specific genes of the lin pathway were found to be housed on regions unique to the UT26S genome [19]; with $\operatorname{lin} A$, $\operatorname{lin} B$, $\operatorname{lin} C$ genes in chromosome $1, \operatorname{lin} F$ on chromosome 2 , and linDER on the plasmid pCHQ1 [19]. The lower pathway genes, including linGHIJ and $\operatorname{linKLMN}$ were found on 


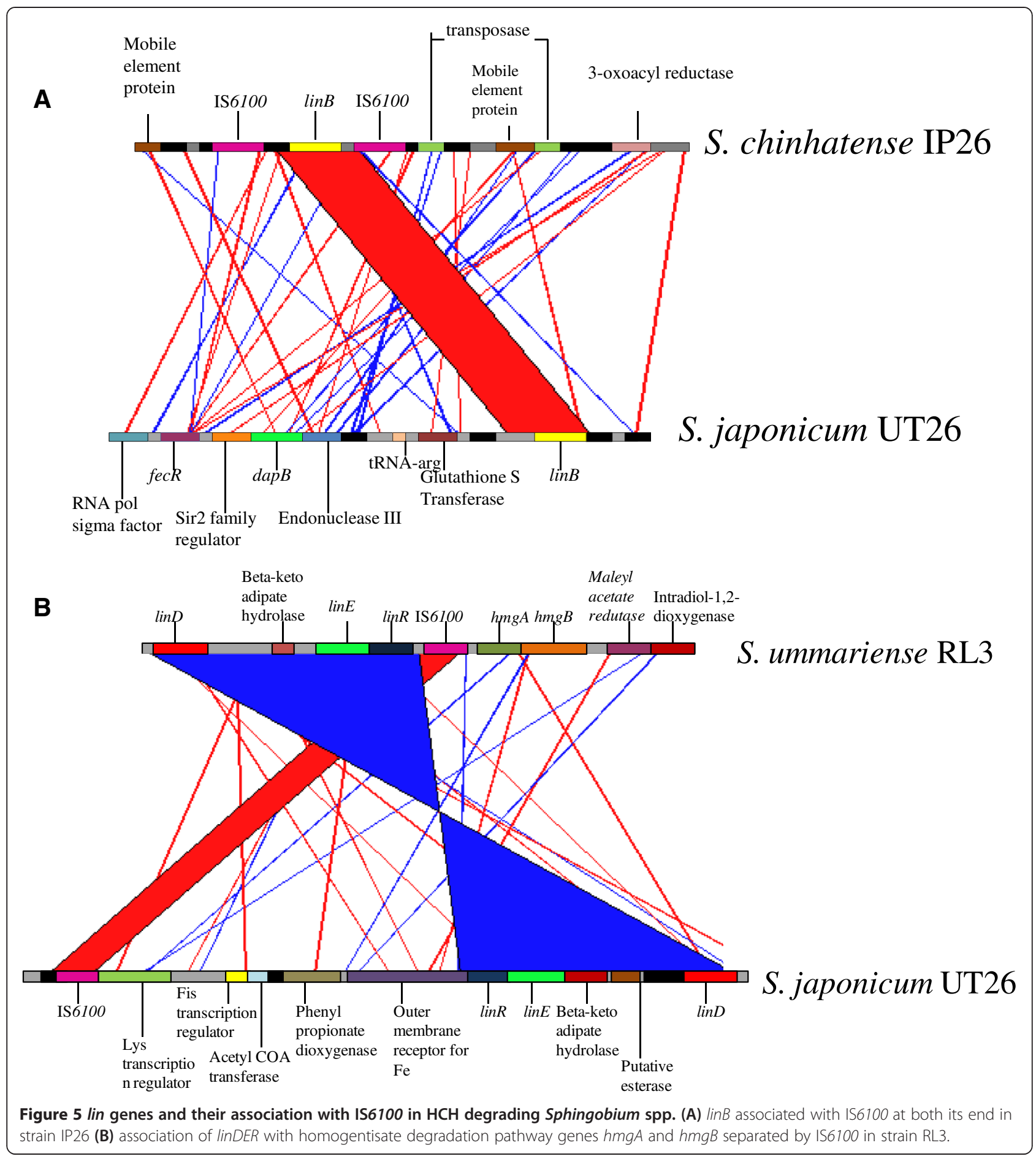

chromosomes 2 and 1, respectively, in regions that were conserved among sphingomonads [19].

Genome recruitment plots were created to map the raw reads of the six novel-sequenced strains to Sphingobium plasmid sequences to investigate the possibility of these plasmids playing a role in transfer of the lin genes. MM-1 plasmids pISP3 and pISP4 in particular were found to have a high percentage of coverage which was maximum with S. ummariense RL3 (Figure 6). As pISP3 houses $\operatorname{lin} D E R$, it is highly probable that plasmid uptake and duplication may explain the triplication of $\operatorname{lin} D E R$ in RL3. The recent metagenomics analysis of the $\mathrm{HCH}$ dumpsite also reflected the enrichment of pISP3, suggesting its availability for other sphingomonads strains present at the $\mathrm{HCH}$ dumpsite [10]. Furthermore, pISP4 encodes $\operatorname{lin} B, \operatorname{lin} C$, and $\operatorname{lin} F$, and similarly shows a high 


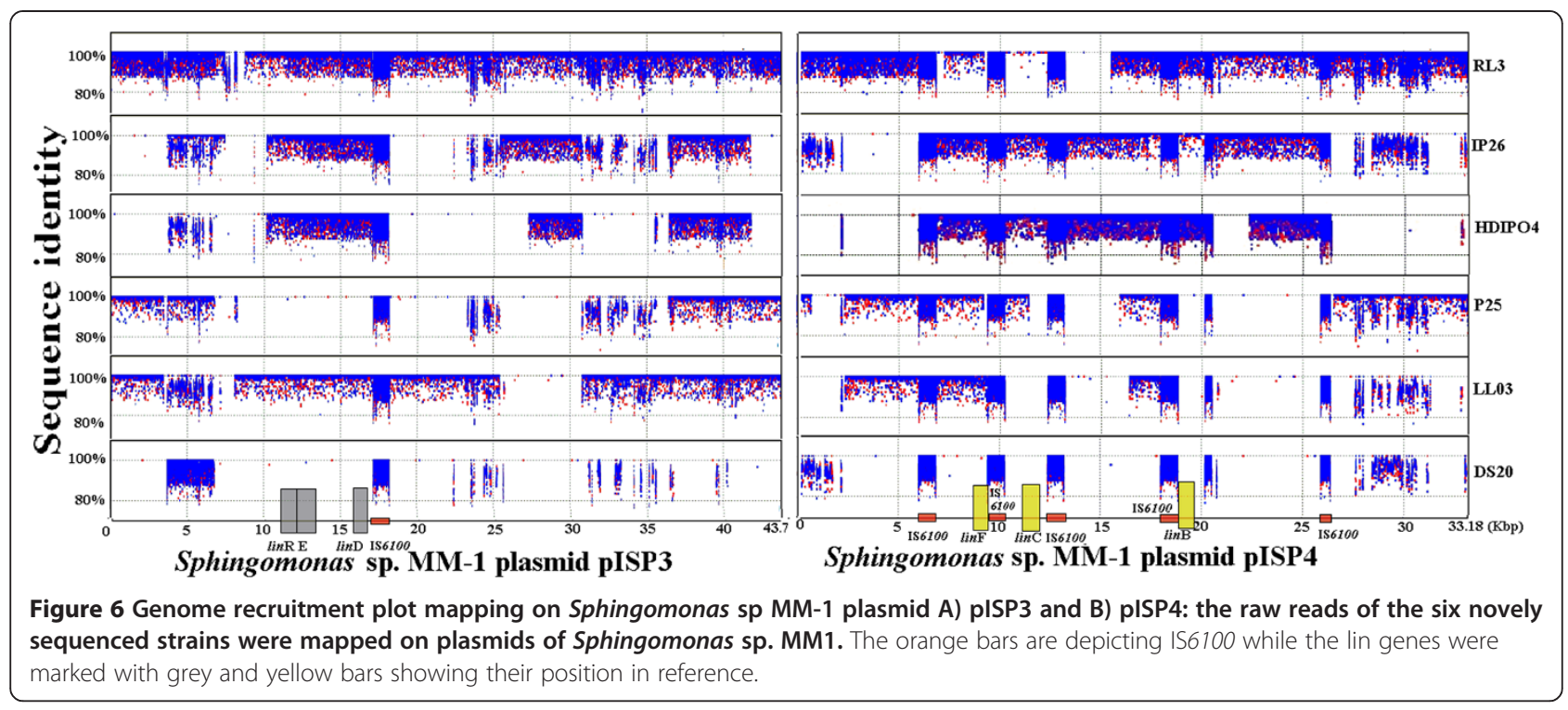

degree of coverage by RL3. Consistent with the absence of $\operatorname{lin} C$ from the RL3 draft genome, which was confirmed by PCR amplification by using the primer $5^{\prime}$-GCGG ATCCGCATGTCTGATTTGAGCGGC-3' and 3'-GCCT CGAGTCAGATCGCGGTAAAGCCGCCGTC-5' ${ }^{\prime}$, there is a gap in the coverage seen in the plasmid region containing $\operatorname{lin} C(11,370$ to $12,122 \mathrm{bp})$, which is a region flanked by two IS6100 elements in MM-1 (Figure 6). This points to the possibility that the plasmid has undergone either acquisition in MM-1 or looping out from RL3 of the linC gene during the course of evolution, mediated directly by IS6100. Mapping the raw reads of the six newly-sequenced Sphingobium strains to the plasmid sequences for MM-1 and UT26S, several of the MM-1 plasmids, but none of the UT26S plasmids demonstrated a high degree of coverage. Additionally, the proportionally higher presence of lin genes on plasmids in MM-1 than in UT26S suggests that strain MM-1 acts as a reservoir for plasmids allowing for the effective spread of the lin system, and thus may be an important strain to include in the consortium development as a potential disseminator of the lin system. Also, strains sharing similar arrangement profile of lin genes with MM-1 i.e., RL3, IP26 and HDIPO4, should be included into designing a consortium.

\section{Strains in transition to acquire lin pathway}

Of the nine sphingomonads under study, seven possessed components of the upper $\mathrm{HCH}$ degradation pathway to varying degrees of completion, and two, SYK6 and DS20, were completely devoid of them (Additional file 1: Table S2). SYK6 did not contain any components of the lin system and the DS20 genome contained only genes of the lower lin pathway- linKLMN an ABC transporter. Of the $\mathrm{HCH}$-degraders, not every strain was found to house the complete array of lin genes characterized in UT26S or
B90A. For instance, the P25 genome lacked $\operatorname{lin} B$, lin C, lin$D E R$, linGH, linI and linJ genes while, strains RL3 and LL03 both lacked $\operatorname{lin} C$ and LL03 lacked $\operatorname{lin} B$, as confirmed by PCR amplificiation (Additional file 1: Table S2). The differential composition of the lin system between these strains may be indicative of different steps in the evolution of the lin pathway, with IP26 in the stage of probable homologous recombination and looping out of $\operatorname{lin} B$, while LL03 shows potential gain of linGHIJ through IS6100-mediated HGT. Strain DS20 possesses ABC transporters and shows potential for acquisition of the lin genes, as it holds 15 copies of IS6100, while P25, in addition to the ABC transporter, has $\operatorname{lin} A$ and $\operatorname{lin} F$ but is yet to acquire the other $\operatorname{lin}$ genes.

lin system sequence diversity and its effect on metabolic efficiency

Upper lin pathway

The upper pathway genes $\operatorname{lin} A, \operatorname{lin} B$ and $\operatorname{lin} C$ degrade $\gamma-\mathrm{HCH}$ and $\alpha-\mathrm{HCH}$, and additionally $\operatorname{lin} B$ acts on $\beta-\mathrm{HCH}$, leading to the formation of $\beta-2,3,4,5,6$-pentachlorocyclohexanol ( $\beta$-PCHL) (Figure 1). As $\alpha$ - and $\beta-\mathrm{HCH}$ form the major components of contamination at the $\mathrm{HCH}$ dumpsite (>80\%), both $\operatorname{lin} A$ and $\operatorname{lin} B$ are extremely important enzymes encoding $\mathrm{HCH}$ dehydrochlorinase and haloalkane dehalogenase, respectively (Figure 1). To gain deeper insights into the lin gene sequence diversity and its impact on $\mathrm{HCH}$ degradation, the genetic divergence of the lin system components was analyzed with respect to the copy number and nucleotide sequence divergence of the lin genes in both upper and lower degradation pathways, using B90A as a reference.

The highest level of divergence in the upper $\mathrm{HCH}$ degradation pathway $\operatorname{lin}$ genes was reported for the $\operatorname{lin} A$ gene encoding for $\mathrm{HCH}$ dehydrochlorinase in B90A [36]. The two previously characterized $\operatorname{lin} A$ variants observed in 
B90A differed by $10 \%$ of their amino acid sequence, and were named $\operatorname{lin} A 1$ and $\operatorname{lin} A 2$. The functional aspects of these variants have been well characterized, as they show enantioselectivity in $( \pm) \alpha-\mathrm{HCH}$ degradation, with LinA1 selective for the $(+)$ and LinA2 for the (-) $\alpha \mathrm{HCH}$ [37]. Also, the degradation ability of LinA1 was found to be lower than that of LinA2 [36]. Among all the lin genes of the upper pathway, $\operatorname{lin} A$ in the present study was found to be most diverged in HDIPO4, in which it appeared to be a hybrid of the two variants ( $\operatorname{lin} A 1$ and $\operatorname{lin} A 2$ ) with $94.8 \%$ sequence similarity to $\operatorname{lin} A 1$ and 92.9 to $\operatorname{lin} A 2$. Near to the catalytic dyad D25 and H73 critical for its enzymatic activity, the HDIPO4 $\operatorname{lin} A$ was found to be identical with $\operatorname{lin} A 1$ [38]. However, the $C$-terminal region corresponded to linA2 (Figure 7A). This hybrid copy, now marked as $\operatorname{lin} A 3$, requires further experimentation, but might be responsible for the comparatively better dehydrochlorination activity of HDIPO4 against $\alpha$ - and $\gamma-\mathrm{HCH}$, as reported earlier [14].

Apart from this divergence of the $\operatorname{lin} A$ sequence in HDIPO4, not such changes to the $\operatorname{lin} A$ gene sequences were observed; all strains showed $100 \%$ sequence similarity to that of the $\operatorname{lin} A 2$ gene [36] with the exception that $\operatorname{lin} A 2$ of RL3 showed a single substitution of L78Q. It is important to mention here that the $\operatorname{lin} A$ gene has already been reported to be under continuous selection pressure and a large number of variants of this gene exist $[7,32,13,39]$ and better variants of $\operatorname{lin} A$ may be used for developing enzymatic bioremediation system for $\mathrm{HCH}$.

In contrast to $\operatorname{lin} A$, there were less variations in $\operatorname{lin} B$ sequences among strains under study. The sequence differences among $\operatorname{lin} A$ and $\operatorname{lin} B$ genes among different Sphingobium spp. are particularly interesting in light of

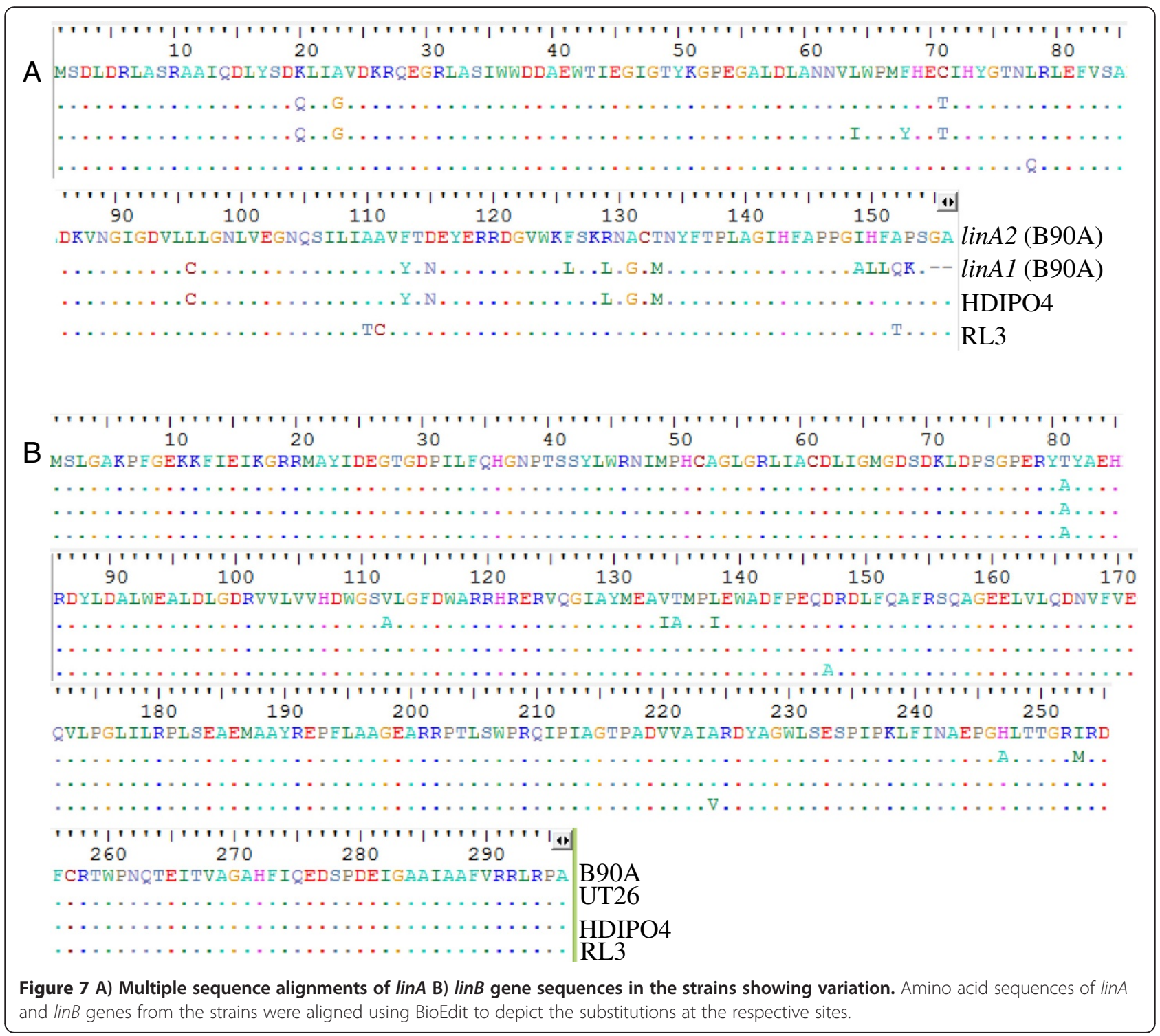


findings that marginal differences in the amino acid sequences of $\operatorname{lin} B$ in UT26S [40], $\mathrm{SP}^{+}$[41], B90A [31], BHC-A [42] and M1205 [43] can alter the efficacy and substrate range, with the former group degrading $\beta-\mathrm{HCH}$ to $\beta$-PCHL and the latter group taking the pathway beyond PCHL to TCHL. HDIPO4 housed two identical $\operatorname{lin} B$ copies with a T81A substitution and overall 99.6\% similarity to B90A while RL3 linB gene had 98.9\% identity, with three substitutions (T81A, D147A and A224V) as compared to $\operatorname{lin} B$ of B90A (Figure 7B). Here, the copy number difference is suspected to have a more impact, as the two copies of $\operatorname{lin} B$ might explain the high $\beta-\mathrm{HCH}$ degradation efficacy of HDIPO4 [14,27]. Apart from these two strains, no such diversity was observed, thus demonstrating the stability of $\operatorname{lin} B$ gene in the population. $\operatorname{lin} C$, which encodes for $\mathrm{HCH}$ dehydrogenase was most conserved among the genes of the upper degradation pathway and demonstrated only a single substitution: Y172C in case of IP26. In any case these studies reflect that $\operatorname{lin} A$ genes are more prone to evolutionary changes under $\mathrm{HCH}$ stress and have not stablized yet.

\section{Lower lin pathway}

The lower pathway of $\gamma-\mathrm{HCH}$ degradation begins from 2,5-Dichlorohydroquinone (2,5-DCHQ) an intermediate of $\gamma-\mathrm{HCH}$ (Figure 1), which is mineralized by the lower pathway lin genes (linDER, linF, linGHIJ, and linKLMN) [6]. In contrast to the upper degradation pathway, very less is known about the divergence and polymorphisms of the genes of the lower degradation pathway.

Among all the lin genes of the lower pathway, $\operatorname{lin} F$ was the most highly conserved, as its amino acid sequence was
$100 \%$ identical in all genomes (Figure 8). In the linDER operon, the set of $\operatorname{lin} D$ genes similarly showed minimal divergence, with the IP26, RL3, and LL03 genes sharing a substitution of N82S, and additionally IP26 having a substitution Q30P. Further, $\operatorname{lin} R$ and $\operatorname{lin} E$ had very little divergence; linR diverged only in one substitution in HDIPO4 (L12P) and $\operatorname{lin} E$ was $100 \%$ identical in all strains. This highlights the fact that the linDER operon, which makes up the backbone of the downstream $\mathrm{HCH}$ degradation pathway, remained highly stable during the course of evolution. A greater degree of the variation of this operon was found, however, in copy number, as RL3 and HDIPO4 housed three and two copies, respectively (Figure 8 \& Additional file 1: Table S2).

In particular linGH, linI and linJ, which mediate the later stages of the lower degradation pathway, i.e., conversion of $\beta$-ketoadipate to succinyl CoA and acetyl CoA (Figure 1), showed variation in the sequences of $\operatorname{linH}$ and linI, whereas $\operatorname{lin} G$ and $\operatorname{lin} J$ sequences were $100 \%$ conserved among all these strains. Here, $\mathrm{linH}$ of HDIPO4 and IP26 were similar to each other, and both diverged from B90A with $99.06 \%$ identity. They held two substitutions (I31V and $\mathrm{N} 171 \mathrm{H}$ ) while LL03 shared the I31V substitution and additionally had a N131D substitution. linI was found to be identical in HDIPO4 and IP26, with a single substitution (A188T) and 99.62\% identity to B90A, while LL03 had two substitutions (A9T and A185V) and 99.25\% identity. However, the significance of sequence divergence in $\operatorname{lin} G$, linH, linI, and linJ genes among these strains is yet to be investigated.

Another important lin gene system of the lower pathway is the $\mathrm{ABC}$ transporter system i.e., $\operatorname{lin} K$, $\operatorname{lin} L$, $\operatorname{lin} M$,

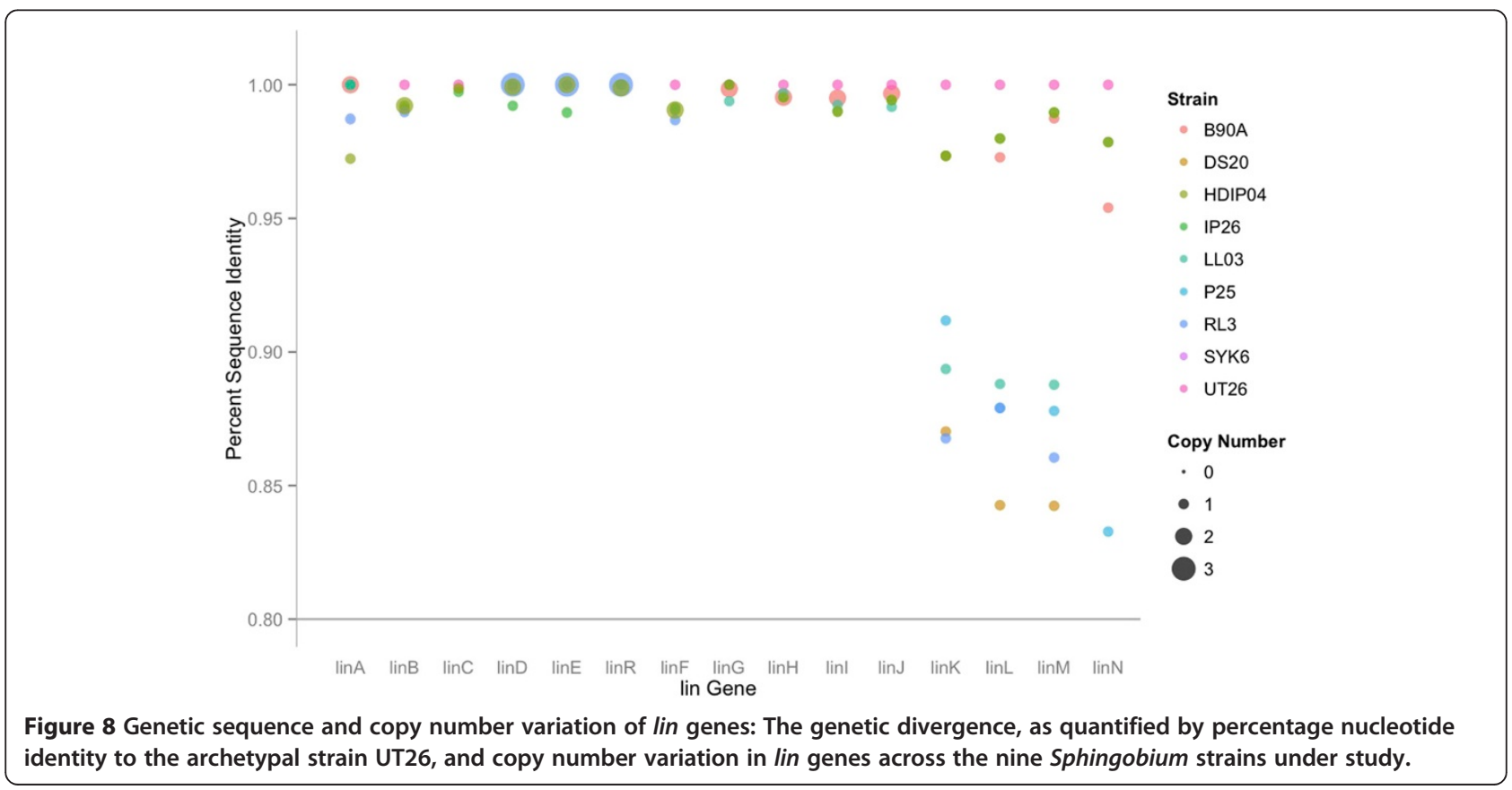


and $\operatorname{lin} N$, which encode a permease, ATPase, periplasmic protein, and lipoprotein, respectively. This ABC transpoter system is very important as it allows for the transport of $\mathrm{HCH}$ isomers and clearance of dead-end metabolites of $\mathrm{HCH}$ from the cell [21]. Out of the entire lin system these genes have shown the highest level of of divergence with $\operatorname{lin} K$ at $86.8 \%$ in RL3, $\operatorname{lin} L$ at $84.3 \%$ in DS20, $\operatorname{lin} M$ at $84.2 \%$ in DS20 and $\operatorname{linN}$ at $83.3 \%$ in P25. Based on the prevalence of similar but non lin-specific $\mathrm{ABC}$ type transporters which are found by sequence identity searches across a variety of microbial species, it is hypothesized that the linKLMN operon derived from convergent evolution in response to environment changes. With the introduction of the $\mathrm{HCH}$ to the environment, pre-existing $\mathrm{ABC}$-type transporters were likely recruited to the $\mathrm{HCH}$ degradation pathway, and thus several genetic variants might have undergone convergent evolution to select for transporters with increased efficiency for $\mathrm{HCH}$-metabolite efflux, and these later generation genes were the one that subsequently underwent HGT. This is in contrast to the likely origin of the $\operatorname{lin} D E R$ operon, which encodes more highly $\mathrm{HCH}$-specific enzymatic functions and is almost perfectly conserved, and thus was likely generated once, and spread through HGT from a single genetic ancestor. The lin pathway shows a characteristic pattern in which the upper $\mathrm{HCH}$ degradation pathway was diverged along a gradient from the most, linA (highly diverged) to the least, linC (least diverged). While in the lower degradation pathway linKLMN was the most highly diverged, followed by linGHIJ, linDER and linF respectively.

In literature, the degradation ability of these strains under consideration is in the order: HDIPO4 $>$ IP26>RL3. In order to further substantiate the relationship between lin system diversity and degradation efficiency, principle component analysis (PCA) was performed on the copy number and sequence divergence for these strains, with $\mathrm{HCH}$ degradation plotted as a supplementary variable to visualize correlation. The analysis demonstrated a close grouping of the four lin-deficient strains, i.e. SYK6, DS20, LL03, and P25 under PCA 1 and 2 (accounting for 32.57 and $24.99 \%$ of the variation in these strains, respectively) (Figure 9A). HDIPO4 and IP26 were colocalized in quadrant 4, opposite from the non-degrader cluster in terms of both dimension 1 and dimension 2, which is appropriate given that these two strains have degradation rates documented to be faster than archetypal strains UT26S and B90A [14] (Figure 9A). While copy number variation for $\operatorname{lin} F, \operatorname{lin} D E R$, and $\operatorname{lin} B$ were mapped most closely to the $\mathrm{HCH}$ degradation vector (Figure 9B), the copy numbers for $\operatorname{lin} C$, linGHIJ and again $\operatorname{lin} B$ played a more important role in differentiating these strains, as they correlated significantly to PCA1 ( $\mathrm{p}$ values $5.897964 \mathrm{e}-05,2.998361 \mathrm{e}-02$, and $1.206315 \mathrm{e}-02$, respectively). In terms of sequence, $\operatorname{lin} A$ and $\operatorname{lin} R$ showed high correlation to degradation ability (Figure 9B), while $\operatorname{lin} L$, $\operatorname{lin} M$, and $\operatorname{lin} K$ were significantly correlated to PCA1 (p values 1.340825e-04, 2.934465e-04, 4.192410e04, respectively) and $\operatorname{lin} I, \operatorname{lin} H, \operatorname{lin} C, \operatorname{lin} B$, and $\operatorname{lin} F$ were the most significant contributors to PCA2 ( $\mathrm{p}$ values 0.0007954298, 0.0010696278, 0.0105835905, 0.0107931486, 0.0222238515 , respecitvely). This suggests that while variation can be seen throughout the lin pathway and the copy number of $\operatorname{lin} F$, $\operatorname{lin} D E R$ and $\operatorname{lin} B$ sequence for $\operatorname{lin} A$ and $R$ might have the most impact in optimizing the efficacy of an $\mathrm{HCH}$ enzymatic bioremediation system.

\section{Genes under diversifying natural selection}

To identify the substitutions that have fixed along the independent lineages and their direction of evolution, $\mathrm{dN} / \mathrm{dS}$ (rate of non-synonymous over synonymous substitution) analysis was performed for sets of orthologous genes, and in particular those responsible for the degradation of $\mathrm{HCH}$, phenol/toluene, homogentisate, chlorophenol and transposons/integrases (Figure 10). The genes of interest found to be under diversifying selection $(\mathrm{dN} /$ $\mathrm{dS}>1$ ) includes those for Fe(II) dependent oxygenase, $\mathrm{ABC}$ transporters, assimilatory nitrate reductase, and general secretory pathway protein. These genes are largely associated with stress tolerance. As mentioned earlier, ABC transporters are involved in uptake of high molecular weight pharmacological agents including xenobiotic compounds [44]. Hence, these transporters and their activity are crucial for their capability of $\mathrm{HCH}$ degradation and other aromatic compounds and likewise, their positive selection indicates the importance of their function in the $\mathrm{HCH}$-stressed environments from which these bacterial strains were isolated. Additionally, nitrate reductase catalyzes the conversion of nitrate into free nitrogen and likely would enable the Sphingobium spp. to more effectively enact a nitrogen stress response. Finally, the diversification of genes such as oxygenases, secretory pathway proteins and translocase components adds to the sphingomonads skill of degradation of a wide range of aromatic compounds. Notably, only $\operatorname{lin} H$ has shown the $\mathrm{dN} / \mathrm{dS}>1$, while the other lin genes did not. This clearly indicates that under strong $\mathrm{HCH}$ pressure, the whole lin pathway is likely to get stabilized in the population with more synonomous substitutions compared to non-synonomous ones and tends to be retained in the population.

\section{Conclusions}

In sequencing the genomes of six novel Sphingobium species and comparing these to the known genomes of three other Sphingobium species, this study has begun to probe the natural variation in the lin pathway for $\mathrm{HCH}$ degradation. Analysis of the variation in the lin system, as well as in the phylogenetic relationships, core genomes, 

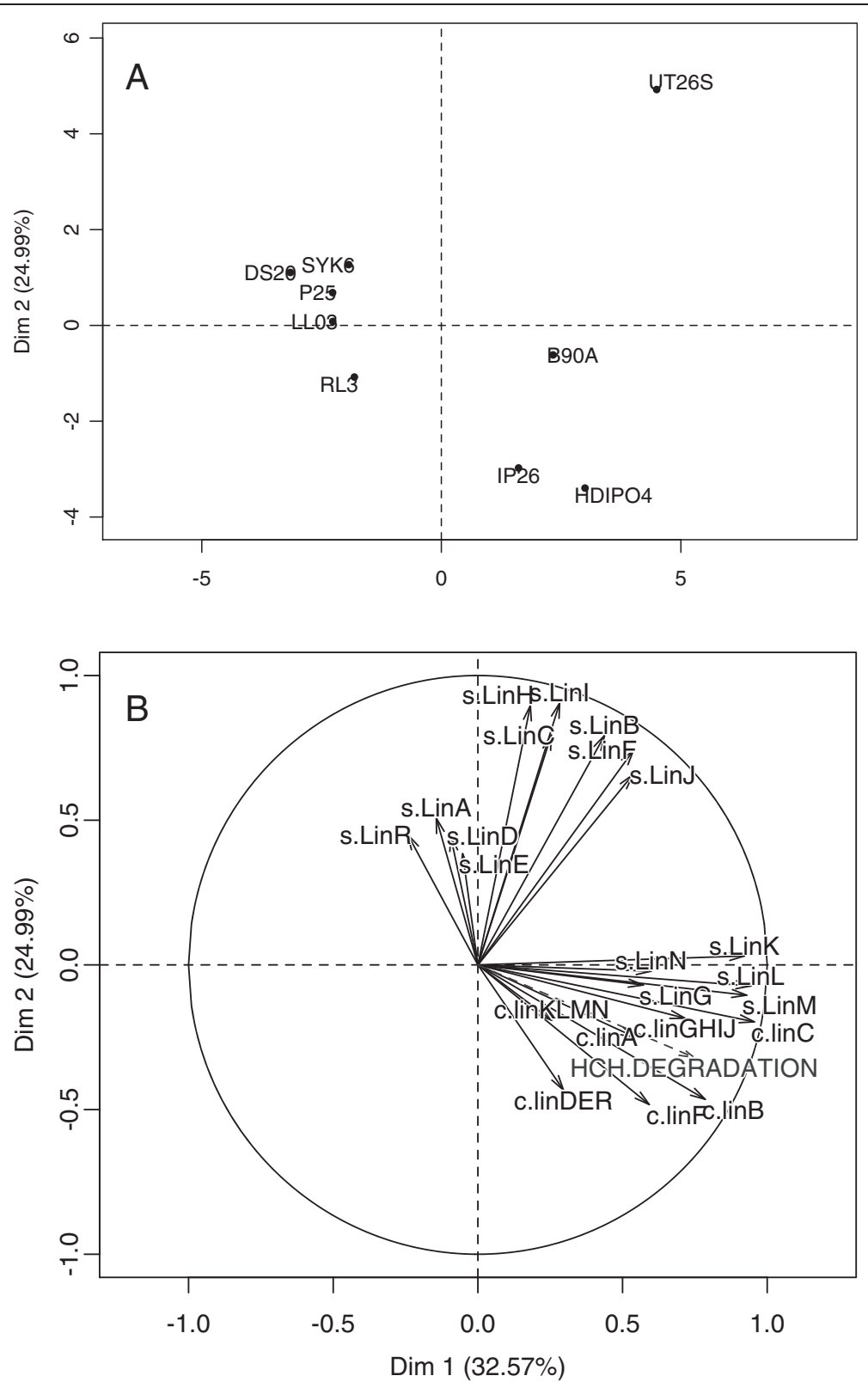

Figure 9 Principal Component Analysis of genes involved in $\mathrm{HCH}$ degradation pathway. (A) PCA individual factor plot showing the grouping of the nine Sphingobium strains based upon the sequence divergence and copy number of the set of lin genes. Principle components 1 (accounting for $30.87 \%$ of the variation of the strains) and 2 (14.47\%) were chosen as the separation of the strains by these PCs demonstrated the highest fidelity to known HCH degradation ability. (B) PCA variable factor plot using principle component 1 and 2, showing the contribution of the lin genetic sequences (s.linA, s.linB...) and copy number (c.linA, c.linB...) to the variation of the nine Sphingobium strains. HCH degradation ability was plotted as a supplementary categorical variable (not factored into the PCs), with non-HCH degraders coded as 0, partial degraders as 1 , and complete degraders as 2 .

and functional profiles of these bacterial strains demonstrated unique characteristics of B90A, HDIPO4 and IP26 which could explain their higher efficacy as the degraders of $\mathrm{HCH}$ isomers. The information thus obtained can now be used to select these better-performing strains for the development of a bacterial consortium for on-site bioremediation of the $\mathrm{HCH}$ dumpsites. Focusing on the lin system, analysis of the similarities in the lin genes sequences and varying copy numbers between these strains has identified variations in the specific genes as key differentiators and these key components will be of critical interest as the most effective targets for optimization of an enzymatic bioremediation system. The analysis so far made reflect that better $\operatorname{lin} A$ and $\operatorname{lin} B$ variants can eventually be the ideal candidates for developing an enzymatic bioremediation system. Moreover, this study has uncovered evidence for genus-level 


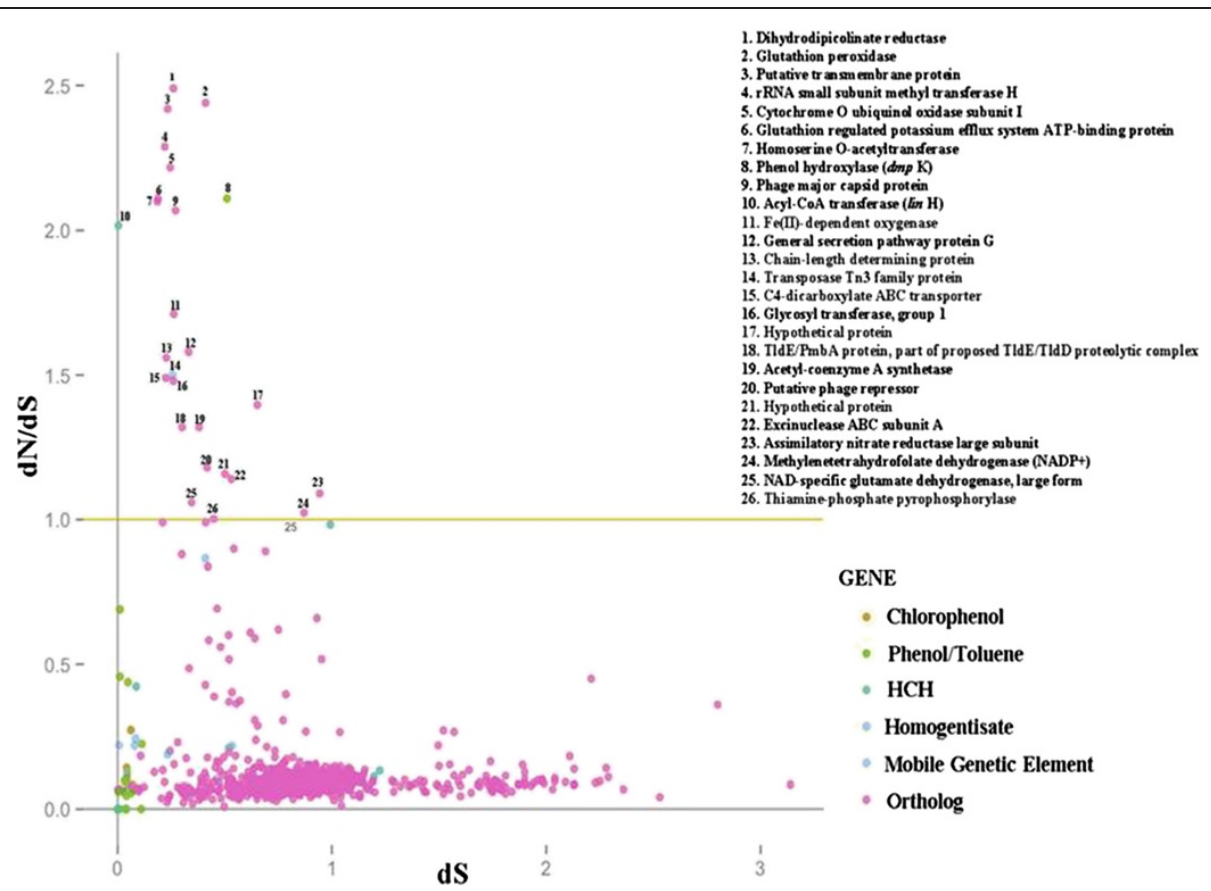

Figure $10 \mathrm{dN} / \mathrm{dS}$ v/s dS plot of orthologs, xenobiotic degradation pathway genes and IS elements/integrases. Sequences of orthologs, xenobiotic degradation pathway genes and IS elements/Integrases were used for calculating their $\mathrm{dN} / \mathrm{dS}$. Genes having $\mathrm{dN} / \mathrm{dS}$ value $>1$ are under positive natural selection.

HGT of plasmids housing components of the lin system, specifically between Sphingomonas sp. MM-1 and RL3. The additional lin-deficient strains are of further importance as they demonstrate varying degrees of acquisition of the lin system and will be useful in future homologous recombination studies to work with manipulated pathway completion through introduction of synthetic lin genes.

\section{Methods}

Selection and sequencing of the Sphingobium genomes Six Sphingobium strains isolated from $\mathrm{HCH}$ dumpsites and demonstrating a range of $\mathrm{HCH}$ degradation abilities were selected for genome sequencing. Five of these Sphingobium strains i.e. S. lactosutens DS20 ${ }^{\mathrm{T}}$ [26], S. chinhatense IP26 ${ }^{\mathrm{T}}$ [27], S. ummariense RL3 ${ }^{\mathrm{T}}$ [28], S. quisquilarium $\mathrm{P} 25^{\mathrm{T}}$ [29], and Sphingobium sp. HDIPO4 were isolated from an $\mathrm{HCH}$ dumpsite in Chinhat village, Lucknow, India whereas, Sphingobium baderi LL03 $^{\mathrm{T}}$ [30], was isolated from an $\mathrm{HCH}$ dumpsite in Spolana, Czech Republic. In addition to these six strains, the genomes of an additional three strains: Sphingobium indicum B90A [45], Sphingobium japonicum UT26S [46], and Sphingobium sp SYK6 [47], were included as references in the study.

Genomic DNA was extracted from $5 \mathrm{ml}$ pure culture pellets grown in Luria Bertani at $28^{\circ} \mathrm{C}$ until O.D. 1.0 or 1.2 using the SuperCos method [48]. DNA concentrations were quantified using NanoDrop spectrophotometer (NanoDrop
Technologies Inc, Wilmington, DE, USA). For all the genomes, sequencing was performed using both the Illumina HighSeq 2000 and 454 GS-FLX Titanium platforms. For sequencing, a $2 \mathrm{Kbp}$ paired end sequencing library was constructed, yielding $\sim 100 \times$ coverage for each genome. An additional three Sphingobium genomes i.e. Sphingobium japonicum UT26S, S. indicum B90A and Sphingobium sp. SYK6 were retrieved to be used as references for this comparative analysis (Table 1).

\section{Genome assembly, annotation, and functional profiling}

The sequencing data were assembled using ABySS 1.3.3 [49] at various k-mer lengths optimized for each genome. Detailed statistics of the genome assemblies are provided in Table 2. The assembly was validated using paired-end information on the Burrows-Wheeler Aligner 0.5.9 (BWA) [50]. The accession numbers and details of the genomes used in this study are provided under Table 1 [51-56]. CDS were predicted using Glimmer-3 [57] and annotated on RAST 4.0 Server [58] for both the draft and complete genomes.

For functional profiling, coding sequences were extracted from the RAST server for all the genomes, and orthologous genes were determined using all-versus-all BLASTP at default parameters [59]. This was validated by using CD-HIT [60] to produce sets of non-redundant representative sequences (query coverage $\geq 80 \%, 0.8$ sequence 
Table 2 Detail statistics of genome assembly of Sphingobium spp.

\begin{tabular}{|c|c|c|c|c|}
\hline Organism (Genome status) & Assembler & K-mer length & No. of Contigs/Chromosomes \& Plasmids & N50 (in Kb) \\
\hline S. baderi LL03 ${ }^{\top}$ (Draft) & ABySS 1.3.3 & 47 & 92 & 269 \\
\hline S. lactosutens $\mathrm{DS} 20^{\mathrm{T}}$ (Draft) & ABySS 1.3.3 & 53 & 110 & 303 \\
\hline Sphingobium sp. HDIPO4 (Draft) & ABySS 1.3.3 & 53 & 143 & 172 \\
\hline S. chinhatense IP26 ${ }^{\top}$ (Draft) & ABySS 1.3.3 & 61 & 236 & 142 \\
\hline S. quisquilarium $\mathrm{P} 25^{\top}$ (Draft) & ABySS 1.3.3 & 47 & 181 & 45 \\
\hline S. ummariense $\mathrm{RL}^{\mathrm{T}}$ (Draft) & ABySS 1.3 .3 & 57 & 139 & 363 \\
\hline S. indicum $\mathrm{B} 9 \mathrm{~A}^{\top}$ (Draft) & ABySS 1.2.7 & 41 & 149 & 54.5 \\
\hline S. japonicum UT26S ${ }^{\top}$ (Draft) & PHRAP and CONSED & - & $\begin{array}{l}\text { Chromosome } 1 \text { (3,514,822 bp), chromosome } \\
2(681,892 \mathrm{bp}), \mathrm{pCHQ} 1(190,974 \mathrm{bp}), \text { pUT1 } \\
(31,776 \mathrm{bp}) \text { ans pUT2 (5,398 bp) }\end{array}$ & - \\
\hline Sphingobium sp. SYK6 & PHRED/PHRAP/CONSED & - & chromosome 1 (4,199,332 bp) and pSLGP (148,801bp) & - \\
\hline
\end{tabular}

identity cut-off). The putative protein coded for each cluster was identified through performing BLASTP on a representative amino acid sequence from each cluster. Comparison of the annotated genomes were also carried out in MicroScope server [61].

Further, the coding sequences were processed for functional annotation using the bi-directional best-hit $(\mathrm{BBH})$ assignment method on KEGG Automatic Annotation Server (KAAS) [62]. This annotation was then used for biological family construction using protein family prediction on MinPath [63]. The top 50 subsystems were selected based on normalized values obtained by dividing with the lowest value for the genes in the respective pathways. Finally, the nine Sphingobium strains and enriched pathways were clustered heirarchially using Pearson correlation with $0.8 \%$ minimum abundance and a heat map was constructed in MeV4.9.0 [64]. Genomic Islands (GIs) were analysed using the IslandViewer software tool (http://www.pathogenomics.sfu.ca/islandviewer) [65]. The CRISPR Finder online server was used to identify CRISPR elements in the draft genomes [66], which were further analyzed to trace their sources.

\section{Phylogenetic analysis of Sphingobium spp.}

The phylogenetic analyses were performed using four different methods.

i) 16S rRNA gene sequences: which were retrieved using BLASTN $\left(\right.$ E-value $\left.=10^{-5}\right)$ [59]. The $16 \mathrm{~S}$ rRNA sequences were aligned using CLUSTALX [67] and subsequently a phylogenetic tree was constructed using the TreeconW software package version 1.3b [68] with the Jukes \& Cantor model (1969) [69] and Neighbor Joining algorithm (bootstrap value $=1000$ ).

ii) Single Copy Gene Sequences: The amino acid sequences of 28 universally present single copy genes (dnaA, frr, gyrB, infB, mnmA, nusA, pheS, rplB, rplC, rplM, rplS, rpoA, rpsB, rpsC, rpsH, rpsI, rpsJ, rpsS, trmD, tef, ychF, alaS, rplE, uvrC, lepA,
rplI, rplP and rplD) were retrieved and concatenated. Further, they were aligned using CLUSTALX (as described above) and their phylogeny was constructed using TreeconW software package version $1.3 \mathrm{~b}$ with the Poisson correction model and Neighbor Joining algorithm (bootstrap value $=1000$ ).

iii) Tetranucleotide Correlation: Whole-genome based tetranucleotide correlation was performed using TETRA software [70], based on which a Pearson correlation matrix was constructed. This was followed by hierarchial clustering on the resultant matrix using MeV4.9.0 [39] and finally a dendrogram was constructed in MEGA4 [71].

iv) Average Nucleotide Identity (ANI): This method includes all possible pairwise comparisons between these genomes as described by Konstantinidis and Tiedje (2005) [18]. Pearson correlation matrices were constructed from these ANI values, which were then used to perform hierarchical clustering followed by a dendrogram construction as described above.

\section{Identification of genes under diversifying natural} selection

Orthologs, genes involved in the degradation of aromatic compounds including $\mathrm{HCH}$, and genes for transposable elements were analyzed for positive selection by extracting their sequences and performing codon by codon alignment on CLUSTALX [67]. These $\mathrm{dN} / \mathrm{dS}$ and $\mathrm{dS}$ values, calculated for each gene pair using Hyphy 2.1.2 [72], were plotted to show the time-independent evolution of the genes.

\section{Arrangement and diversification of the lin catabolic system}

The Artemis Comparison Tool (Web-ACT) [73] was used to compare the arrangement of the lin genes and proximal genetic mobility elements such as IS6100 with 
reference to lin arrangement in S. japonicum UT26S. After constructing a database of the contigs for each strain, genes for $\mathrm{HCH}$ degradation were extracted using BLASTN [59], and the percent identity to the respective gene in the archetypal strain UT26S was used as a measure of genetic divergence. This divergence was plotted in addition to copy number values for each gene in each strain using the $\mathrm{R}$ package ggplot2 [74]. Principle component analysis (PCA) with the copy number and divergence data was then done with the $\mathrm{R}$ package FactoMine R [75], with $\mathrm{HCH}$ degradation plotted as a supplementary discrete variable ( 0 - complete non degrader, 1- partial degrader, 2- full degrader), followed by a plot construction with ggplot2. Recruitment plots of the raw reads of the six Sphingobium spp. mapped against the sequence of all the plasmids of Sphingomonas sp MM-1 (extracted from NCBI) were created using MUMmer 3.23 [76].

\section{Availability of supporting data}

The supporting data has been deposited in Dryad (http:// datadryad.org/) with doi:10.5061/dryad.g7t27.

\section{Additional file}

Additional file 1: Table S1. Genes cluster identified for the degradation of aromatic hydrocarbons. Table S2. lin genes copy number within the Sphingobium genomes.

\section{Competing interests}

The authors declare that they have no competing interests.

\section{Authors' contributions}

$H V$, RK and PO have carried out the analysis of data and written the manuscript drafts. NS, RK, PO and HV have designed the experiments. RL, NS, JPK and JAG have critically reviewed the manuscript. RL has given the final approval to the manuscript to published. All authors read and approved the final manuscript

\section{Acknowledgements}

The work was supported by Grants from the Department of Biotechnology (DBT), Government of India under project BT/PR3301/BCE/8/875/11, All India Network Project on Soil Biodiversity-Biofertilizer (ICAR), Department of Science and Technology under project SR/SO/AS-24/2011, University of Delhi/Department of Science and Technology, Promotion of University Research and Scientific Excellence (PURSE)-DU-DST_-PURSE GRANT. H.V., R.K., P.O., and N.S. gratefully acknowledge the Council for Scientific and Industrial Research (CSIR), the National Bureau of Agriculturally Important Microorganisms (NBAIM) (AMASS/2006-07/NBAIM/CIR) and the Fulbright Program for providing research fellowships.

\footnotetext{
Author details

'Room No. 115, Molecular Biology Laboratory, Department of Zoology, University of Delhi, Delhi 110007, India. ${ }^{2}$ Interdisciplinary Centre for Plant Genomics \& Department of Plant Molecular Biology, University of Delhi, South Campus, New Delhi, India. ${ }^{3}$ Argonne National Laboratory, 9700 South Cass Avenue, Argonne, IL 60439, USA. ${ }^{4}$ Department of Ecology and Evolution, University of Chicago, 5640 South Ellis Avenue, Chicago, IL 60637, USA.
}

Received: 10 May 2014 Accepted: 23 October 2014

Published: 23 November 2014

\section{References}

1. Takeuchi M, Hamana K, Hiraishi A: Proposal of the genus Sphingomonas sensustricto and three new genera, Sphingobium, Novosphingobium and Sphingopyxis, on the basis of phylogenetic and chemotaxonomic analyses. Int J Syst Evol Microbiol 2001, 51:1405-1417.

2. Maruyama T, Park HD, Ozawa K, Tanaka Y, Sumino T, Hamana K, Hiraishi A, Kato K: Sphingosinicella microcystinivorans gen. nov., sp. nov., a microcystin-degrading bacterium. Int I Syst Evol Microbiol 2006, 56:85-89.

3. Balkwill DL, Fredrickson J, Romine M: From Sphingomonas and Related Genera. In The Prokaryotes: A Handbook on the Biology of Bacteria. Volume 7. Edited by Stackebrandt E. Singapore: Springer; 2006:605-629.

4. Li YF: Global technical hexachlorocyclohexane usage and its contamination consequences in the environment: from 1948 to 1997. Sci Total Environ 1999, 232:121-158.

5. Vijgen J, Yi LF, Forter M, Lal R, Weber R: The legacy of lindane and technical HCH production. Organohalog Comp 2006, 68:899-904.

6. Lal R, Pandey G, Sharma P, Kumari K, Malhotra S, Pandey R, Raina V, Kohler HPE, Holliger C, Jackson C, Oakeshott JG: The biochemistry of microbial degradation of hexachlorocyclohexane $(\mathrm{HCH})$ and prospects for bioremediation. Microbiol Mol Biol Rev 2010, 74:58-80.

7. Boltner D, Moreno-Morillas S, Ramos JL: $16 \mathrm{~S}$ rDNA phylogeny and distribution of lin genes in novel hexachlorocyclohexane-degrading Sphingomonas strains. Environ Microbiol 2005, 7:1329-1338.

8. Dadhwal M, Singh A, Prakash O, Gupta SK, Kumari K, Sharma P, Jit S, Verma M, Holliger C, Lal R: Proposal of biostimulation for hexachlorocyclohexane ( $\mathrm{HCH})$-decontamination and characterization of culturable bacterial community from high-dose point $\mathrm{HCH}$-contaminated soils. J App/ Microbiol 2009, 106:381-392.

9. Sangwan N, Lata P, Dwivedi V, Singh A, Niharika N, Kaur J, Anand S, Malhotra J, Jindal S, Nigam A, Lal D, Dua A, Saxena A, Garg N, Verma M, Kaur J, Mukherjee U, Gilbert JA, Dowd SE, Raman R, Khurana P, Khurana JP, Lal R: Comparative metagenomic analysis of soil microbial communities across three hexachlorocyclohexane contamination levels. PLOS ONE 2012, 7:e46219.

10. Sangwan N, Verma H, Kumar R, Negi V, Lax S, Khurana P, Khurana JP, Gilbert JA, Lal R: Reconstructing an ancestral genotype of two hexachlorocyclohexane degrading Sphingobium species using metagenomic sequence data. ISME J 2013, doi: 10.1038/ismej.2013.153.

11. Nagata Y, Miyauchi K, Takagi M: Complete analysis of genes and enzymes for gamma-hexachlorocyclohexane degradation in Sphingomonas paucimobilis UT26. J Ind Microbiol Biotechnol 1999, 23:380-390.

12. Nagata $Y$, Endo $R$, Ito M, Ohtsubo $Y$, Tsuda M: Aerobic degradation of lindane ( $\gamma$-hexachlorocyclohexane) in bacteria and its biochemical and molecular basis. Appl Microbiol Biotechnol 2007, 76:741-752.

13. Sharma P, Pandey R, Kumari K, Pandey G, Jackson CJ, Russell RJ, Oakeshott JG, Lal R: Kinetic and sequence-structure-function analysis of known LinA variants with different hexachlorocyclohexane isomers. PLOS ONE 2011, 6:e25128.

14. Geueke B, Garg N, Ghosh S, Fleischmann T, Holliger C, Lal L, Kohler HPE: Metabolomics of hexachlorocyclohexane $(\mathrm{HCH})$ transformation: ratio of $\mathrm{LinA}$ to LinB determines metabolic fate of $\mathrm{HCH}$ isomers. Environ Microbiol 2013, 15:1040-1049.

15. Aylward FO, McDonald BR, Adams SM, Valenzuela A, Schmidt RA, Goodwin LA, Woyke TA, Currie CA, Suen G, Poulsen M: Comparison of 26 sphingomonad genomes reveals diverse environmental adaptations and biodegradative capabilities. Appl Environ Microbiol 2013, 79:3724-3733.

16. Sorek R, Lawrence CM, Wiedenheft B: CRISPR-mediated adaptive immune system in bacteria and archaea. Annu Rev Biochem 2013, 82:237-266.

17. Bhaya D, Davison M, Barrangou R: CRISPR-Cas systems in bacteria and archaea: versatile small RNAs for adaptive defense and regulation. Annu Rev Genet 2011, 45:273-297.

18. Konstantinidis K, Tiedje J: Genomic insights that advance the species definition for prokaryotes. PNAS 2004, 102:2567-2572.

19. Nagata $Y$, Natsui $S$, Endo R, Ohtsubo Y, Ichikawa N, Ankai A, Oguchi A, Fukui S, Fujita N, Tsuda M: Genomic organization and genomic structural rearrangements of Sphingobium japonicum UT26S, an archetypal $\gamma$-hexachlorocyclohexane-degrading bacterium. Enzyme Microb Technol 2011, 49:499-508.

20. Jit S, Dadhwal M, Kumari H, Jindal S, Kaur J, Lata P, Niharika N, Lal D, Garg N, Gupta SK, Sharma P, Bala K, Singh A, Vijgen J, Weber R, Lal R: Evaluation of 
hexachlorocyclohexane contamination from the last lindane production plant operating in India. Environ Sci Pollut Res Int 2011, 18:586-597.

21. Endo $R$, Ohtsubo $Y$, Tsuda $N$, Nagata $Y$ : Identification and characterization of genes encoding a putative ABC-type transporter essential for utilization of gamma-hexachlorocyclohexane in Sphingobium japonicum UT26. J Bacteriol 2007, 189:3712-3720.

22. Ninfa AJ, Magasanik B: Covalent modification of the glnG product, NRI, by the gInL product, NRII, regulates the transcription of the gInALG operon in Escherichia coli. Proc Natl Acad Sci U S A 1986, 83:5909-5913.

23. Scott N, Hess M, Bouskill NJ, Mason OU, Jansson JK, Gilbert JA: The microbial nitrogen cycling potential is impacted by polyaromatic hydrocarbon pollution of marine sediments. Front Microbiol 2014, 5: doi:10.3389/fmicb.2014.00108.

24. Ninfa AJ, Ninfa EG, Lupas AN, Srock A, Magasanik B, Stock J: Crosstalk between bacterial chemotaxis signal transduction proteins and regulators of transcription of the Ntr regulon: evidence that nitrogen assimilation and chemotaxis are controlled by a common phosphotransfer mechanism. Proc Natl Acad Sci U S A 1988, 85:5492-5496.

25. Pal R, Bala S, Dhingra G, Prakash O, Dadhwal M, Kumar M, Prabagaran SR, Shivaji S, Cullum J, Holliger C, Lal R: The hexachlorocyclohexanedegrading bacterial strains Sphingomonas paucimobilis B90A, UT26S and $\mathrm{Sp}+$ having similar lin genes are three distinct species, Sphingobium indicum sp. nov; S. japonicum sp. nov; and S. francense sp. nov. and reclassification of [Sphingomonas] chungbukensis as Sphingobium chungbukense comb. nov. Int I Syst Evol Microbiol 2005, 55:1965-1972.

26. Kumari H, Gupta SK, Jindal S, Katoch P, Lal R: Description of Sphingobium lactosutens sp. nov., isolated from a hexachlorocyclohexane dump site and Sphingobium abikonense sp. nov. isolated from oil contaminated soil. Int J Syst Evol Microbiol 2009, 59:2291-2296.

27. Dadhwal M, Jit S, Kumari H, Lal R: Sphingobium chinhatense sp. nov., a hexachlorocyclohexane $(\mathrm{HCH})$ degrading bacterium isolated from an HCH dump site. Int I Syst Evol Microbiol 2009, 59:3140-3144.

28. Singh A, Lal R: A novel hexachlorocyclohexane degrading bacterium Sphingobium ummariense sp. nov. isolated from $\mathrm{HCH}$ contaminated soil. Int J Syst Evol Microbiol 2009, 59:162-166.

29. Bala K, Sharma P, Lal R: Sphingobium quisquiliarum sp. nov., $P 25^{\top}$ a hexachlorocyclohexane $(\mathrm{HCH})$ degrading bacterium isolated from $\mathrm{HCH}$ contaminated soil. Int J Syst Evol Microbiol 2010, 60:429-433.

30. Kaur J, Moskalikova H, Niharika N, Sedlackova M, Hampl A, Damborsky J, Prokop Z, Lal R: Sphingobium baderi sp. nov., isolated from a hexachlorocyclohexane $(\mathrm{HCH})$ dumpsite in Spolana. Int I Syst Evol Microbiol 2012, 63:673-678.

31. Dogra C, Raina V, Pal R, Suar M, Lal S, Gartemann KH, Holliger C, van der Meer JR, Lal R: Organization of lin genes and IS6100 among different strains of hexachlorocyclohexane-degrading Sphingomonas paucimobilis: evidence for horizontal gene transfer. J Bacteriol 2004, 186:2225-2235.

32. Mohn WW, Mertens B, Neufeld J, De Lorenzo V: Distribution and phylogeny of hexachlorocyclohexane-degrading bacteria in soils from Spain. Environ Microbiol 2006, 8:60-68.

33. Malhotra S, Sharma P, Kumari H, Singh A, Lal R: Localization of $\mathrm{HCH}$ catabolic genes (lin genes) in Sphingobium indicum B90A. Indian J Microbiol 2007, 47:271-275.

34. Gai Z, Wang X, Tang H, Tai C, Tao F, Wu G, Xu P: Genome sequence of Sphingobium yanoikuyae XLDN2-5, an efficient carbazole-degrading strain. J Bacteriol 2011, 193:6404-6405.

35. Tabata M, Ohtsubo Y, Ohhata S, Tsuda M, Nagata Y: Complete genome sequence of the gamma-hexachlorohexane-degrading bacterium Sphingomonas sp. Strain MM-1. Genome Announc 2013, 1:e00247-13.

36. Kumari R, Subudhi S, Suar M, Dhingra G, Raina V, Dogra C, Lal S, Holliger C, van der Meer JR, Lal R: Cloning and characterization of lin genes responsible for the degradation of hexachlorocyclohexane isomers in Sphingomonas paucimobilis strain B90. Appl Environ Microbiol 2002, 68:6021-6028

37. Suar M, van der Meer JR, Lawlor K, Holliger C, Lal R: Dynamics of multiple lin gene expression in Sphingomonas paucimobilis B90A in response to different hexachlorocyclohexane isomers. Appl Environ Microbiol 2004, 70:6650-6656

38. Nagata Y, Mori K, Takagi M, Murzin AG, Damborsky J: Identification of protein fold and catalytic residues of $\gamma$-hexachlorocyclohexane dehydrochlorinase LinA. Proteins 2001, 45:471-477.

39. Sharma P, Jindal S, Bala K, Kumari K, Niharika N, Kaur J, Pandey G, Pandey R, Russell RJ, Oakeshott JG, Lal R: Functional screening of enzymes and bacteria for the dechlorination of hexachlorocyclohexane by a highthroughput colorimetric assay. Biodegradation 2013, 25:179-187.

40. Nagata Y, Hatta T, Imai R, Kimbara K, Fukuda M, Yano K, Takagi M: Purification and characterization of $\gamma$-hexachlorocyclohexane $(\gamma-\mathrm{HCH})$ dehydrochlorinase (LinA) from Pseudomonas paucimobilis. Biosci Biotechnol Biochem 1993, 59:1582-1583.

41. Ceremonie H, Boubakri H, Mavingui P, Simonet P, Vogel TM: Plasmid-encoded $Y$-hexachlorocyclohexane degradation genes and insertion sequences in Sphingobium francense (ex-Sphingomonas paucimobilis Sp+). FEMS Microbiol Lett 2006, 257:243-252

42. Wu J, Hong Q, Han P, He J, Li S: A gene linB2 responsible for the conversion of $\beta-\mathrm{HCH}$ and 2,3,4,5,6-pentachlorocyclohexanol in Sphingomonas sp. BHC-A. Appl Microbiol Biotechnol 2007, 73:1097-1105.

43. Ito M, Prokop Z, Klvana M, Otsubo Y, Tsuda M, Damborsky J, Nagata Y: Degradation of beta-hexachlorocyclohexane by haloalkane dehalogenase LinB from gamma-hexachlorocyclohexane-utilizing bacterium Sphingobium sp. MI1205. Arch Microbiol 2007, 188:313-325.

44. Glavinas H, Krajcsi P, Cserepes J, Sarkadi B: The role of ABC transporters in drug resistance, metabolism and toxicity. Curr Drug Deliv 2004, 1:27-42.

45. Anand S, Sangwan N, Lata P, Kaur J, Dua A, Singh AK, Verma M, Kaur J, Khurana JP, Khurana P, Mathur S, Lal R: Genome sequence of Sphingobium indicum B90A, a hexachlorocyclohexane-degrading bacterium. J Bacteriol 2012, 194:4471-4472.

46. Nagata Y, Ohtsubo Y, Endo R, Ichikawa N, Ankai A, Oguchi A, Fukui S, Fujita N, Tsuda M: Complete genome sequence of the representative $\mathrm{Y}$-hexachlorocyclohexane-degrading bacterium Sphingobium japonicum UT26S. J Bacteriol 2010, 192:5852-5853.

47. Masai E, Kamimura N, Kasai D, Oguchi A, Ankai A, Fuki S, Fukui S, Takahashi M, Yashiro I, Sasaki H, Harada T, Nakamura S, Katano Y, Narita-Yamada S, Nakazawa H, Hara H, Katayama Y, Fukuda M, Yamazaki S, Fujitab N: Complete genome sequence of Sphingobium sp. strain SYK-6, a degrader of lignin-derived biaryls and monoaryls. J Bacteriol 2012, 194:534-535.

48. Sambrook J, Fritsch EJ, Maniatis T, Maniatis T (Eds): Molecular Cloning: A Laboratory Manual. Volume 2. 2nd edition. New York: Cold Spring Harbor Laboratory Press; 1989.

49. Simpson JT, Wong K, Jackman SD, Schein JE, Jones SJ, Birol I: ABySS: a parallel assembler for short read sequence data. Genome Res 2009, 19:1117-1123.

50. Li H, Durbin R: Fast and accurate short read alignment with BurrowsWheeler Transform. Bioinformatics 2009, 25:1754-1760.

51. Kaur J, Verma H, Tripathi C, Khurana JP, Lal R: Draft genome sequence of a hexachlorocyclohexane-degrading bacterium, Sphingobium baderi strain LL03'. Genome Announc 2013, 1:e00751-13.

52. Kumar R, Dwivedi V, Negi V, Khurana JP, Lal R: Draft genome sequence of Sphingobium lactosutens strain DS20 isolated from an hexachlorocyclohexane (HCH) dumpsite. Genome Announc 2013, 1:00753-13.

53. Niharika N, Sangwan N, Ahmad S, Singh P, Khurana JP, Lal R: Draft genome sequence of Sphingobium chinhatense strain IP26 ${ }^{\top}$ isolated from the hexachlorocyclohexane dumpsite. Genome Announc 2013, 1:00680-13.

54. Singh AK, Sangwan N, Sharma A, Gupta V, Khurana JP, Lal R: Draft genome sequence of Sphingobium quisquiliarum $\mathrm{P} 25^{\top}$, a novel hexachlorocylohexane $(\mathrm{HCH})$ - degrading bacterium isolated from the HCH dumpsite. Genome Announc 2013, 1:00717-13.

55. Kohi P, Dua A, Sangwan N, Oldach P, Khurana JP, Lal R: Draft genome sequence of Sphingobium ummariense strain RL-3, a hexachlorocyclohexanedegrading bacterium. Genome Announc 2013, 1:00956-13.

56. Mukherjee U, Kumar R, Mahato NK, Khurana JP, Lal R: Draft genome sequence of Sphingobium sp. HDIPO4, an avid degrader of hexachlorocyclohexane. Genome Announc 2013, 1:00749-13.

57. Delcher AL, Bratke KA, Powers EC, Salzberg SL: Identifying bacterial genes and endosymbiont DNA with Glimmer. Bioinformatics 2007, 23:673-679.

58. Aziz RK, Bartels D, Best AA, DeJongh M, Disz T, Edwards RA, Formsma K, Gerdes S, Glass EM, Kubal M, Meyer F, Olsen GJ, Olson R, Osterman AL, Overbeek RA, McNeil LK, Paarmann D, Paczian T, Parrello B, Pusch GD, Reich C, Stevens R, Vassieva O, Vonstein V, Wilke A, Zagnitko O: The RAST server: rapid annotations using subsystems technology. BMC Genomics 2008, 9:75.

59. Altschul SF, Gish W, Miller W, Myers EW, Lipman DJ: Basic local alignment search tool. J Mol Biol 1990, 215:403-410.

60. Li W, Godzik A: Cd-hit: a fast program for clustering and comparing large sets of protein or nucleotide sequences. Bioinformatics 2006, 22:1658-1659. 
61. Vallenet D, Belda E, Calteau A, Cruveiller S, Engelen S, Lajus A, Fèvre FL, Longin C, Mornico D, Roche D, Rouy Z, Salvignol G, Scarpelli C, Smith AAT, Weiman M, Médigue C: MicroScope-an integrated microbial resource for the curation and comparative analysis of genomic and metabolic data. Nucleic Acids Res 2013, 41:D636-D647.

62. Moriya Y, Itoh M, Okuda S, Yoshizawa A, Kanehisa M: KAAS: an automatic genome annotation and pathway reconstruction server. Nucleic Acids Res 2007, 35:W182-W185.

63. Ye Y, Doak TG: A parsimony approach to biological pathway reconstruction/inference for genomes and metagenomes. PLoS Comput Biol 2009, 5:e1000465.

64. Saeed Al, Sharov V, White J, Li J, Liang W, Bhagabati N, Braisted J, Klapa M, Currier T, Thiagarajan M, Sturn A, Snuffin M, Rezantsev A, Popov D, Ryltsov A, Kostukovich E, Borisovsky I, Liu Z, Vinsavich A, Trush V, Quackenbush J: TM4: a free, open-source system for microarray data management and analysis. Biotechniques 2003, 34:374-378.

65. Langille MGI, Brinkman FSL: IslandViewer: an integrated interface for computational identification and visualization of genomic islands. Bioinformatics 2009, 25:664-665.

66. Grissa I, Vergnaud G, Pourcel C: CRISPRFinder: a web tool to identify clustered regularly interspaced short palindromic repeats. Nucleic Acids Res 2007, 35:W52-W57.

67. Larkin MA, Blackshields G, Brown NP, Chenna R, McGettigan PA, McWilliam H, Valentin F, Wallace IM, Wilm A, Lopez R, Thompson JD, Gibson TJ, Higgins DG: Clustal W and Clustal X version 2.0. Bioinformatics 2007, 23:2947-2948.

68. Van de Peer Y, De Wachter Y: TREECON for Windows: a software package for the construction and drawing of evolutionary trees for the Microsoft Windows environment. Comput Applic Biosci 1994, 10:569-570.

69. Jukes TH, Cantor CR: Evolution of protein molecules," in Munro (ed.). Mammalian Protein Metabolism 1969, 3:21-132.

70. Teeling H, Waldmann J, Lombardot T, Bauer M, Glöckner FO: TETRA: a web-service and a stand-alone program for the analysis and comparison of tetranucleotide usage patterns in DNA sequences. BMC Bioinformatics 2004, 5:163.

71. Tamura K, Dudley J, Nei M, Kumar S: MEGA4: Molecular Evolutionary Genetics Analysis (MEGA) software version 4.0. Mol Bioland Evol 2007, 24:1596-1599.

72. Pond SLK, Frost SDW, Muse SV: HyPhy: hypothesis testing using phylogenies. Bioinformatics 2005, 21:676-679.

73. Carver TJ, Rutherford KM, Berriman M, Rajandream MA, Barrell BG, Parkhill J: ACT: the artemis comparison tool. Bioinformatics 2005, 16:3422-3433.

74. Wickham H: Ggplot2: Elegant Graphics for Data Analysis. New York: Springer 2009:213.

75. Le S, Josse J, Husson F: FactoMineR: an R package for multivariate analysis. J Stat Softw 2008, 25:1-18.

76. Kurtz S, Phillippy A, Delcher AL, Smoot M, Shumway M, Antonescu C, Salzberg SL: Versatile and open software for comparing large genomes. Genome Biol 2004, 5:12

doi:10.1186/1471-2164-15-1014

Cite this article as: Verma et al:: Comparative genomic analysis of nine Sphingobium strains: insights into their evolution and hexachlorocyclohexane $(\mathrm{HCH})$ degradation pathways. BMC Genomics 2014 15:1014.

\section{Submit your next manuscript to BioMed Central and take full advantage of:}

- Convenient online submission

- Thorough peer review

- No space constraints or color figure charges

- Immediate publication on acceptance

- Inclusion in PubMed, CAS, Scopus and Google Scholar

- Research which is freely available for redistribution 